\title{
Spatial Assimilation at a Halt? Contextual Mobility across Immigrant Generations in the Norwegian Welfare State ${ }^{\dagger}$
}

\author{
Are Skeie Hermansen ${ }^{1,2}$, Pål Oskar Hundebo ${ }^{3}$ and Gunn Elisabeth Birkelund ${ }^{1}$ \\ ${ }^{1}$ Department of Sociology and Human Geography, University of Oslo \\ ${ }^{2}$ Swedish Institute for Social Research, Stockholm University \\ ${ }^{3}$ Centre for the Study of Professions, Oslo Metropolitan University
}

March 2021

${ }^{\dagger}$ Previous versions of this work was presented at the Culture, Society and Behavior Lab at the University of Oslo, Swedish Institute for Social Research, Norwegian Institute for Social Research, and the at 2019 Annual Meeting of the Population Association of America in Austin, TX, USA. We thank the audiences at these occasions for helpful comments. 


\title{
Spatial Assimilation at a Halt? Contextual Mobility across Immigrant
}

\section{Generations in the Norwegian Welfare State}

\begin{abstract}
We study contextual mobility and neighborhood attainment among immigrant descendants using administrative data from Norway. We find that adult immigrant descendants often remain in neighborhood contexts that largely resemble their childhood neighborhoods, characterized by relative economic disadvantage and comparatively few native-born residents. Intergenerational persistence is strongest among descendants of immigrants from Pakistan, the Middle East, and Africa. Further, group-level differences in individual socioeconomic attainment, family background, and characteristics of their childhood neighborhoods account for a substantial part of the adult native-immigrant gaps in neighborhood-level economic composition, but less so for neighborhood-level proximity to native-born residents. Childhood residential segregation is the most important factor in accounting for adult native-immigrant neighborhood gaps, while individual socioeconomic attainment is of limited influence. Our findings offer only partial support for spatial assimilation theory—which predicts that acculturation and socioeconomic progress will lead to a convergence in neighborhood profiles relative to natives across immigrant generations - but may reflect external barriers in the housing market or persistent residential preferences for (co-ethnic) immigrant neighbors. We speculate whether equalization of neighborhood quality in the Norwegian welfare state weakens the link between spatial disadvantage and immigrant concentration, which could lower immigrant descendants' incentives to move out of immigrant-dense neighborhoods. This may in turn lead to a pattern of 'uneven assimilation' where movement towards spatial assimilation across immigrant generations is stagnating, despite substantial socioeconomic progress among immigrant descendants.
\end{abstract}




\section{INTRODUCTION}

Place-based inequalities pose challenges to twenty-first century multiethnic societies, as newcomer immigrant minorities often concentrate in areas characterized by relative socioeconomic disadvantage and spatial isolation from natives (Alba and Foner 2015; Musterd 2005). Large-scale migration from low-income origin countries to rich countries in the West re-actualizes old questions of the spatial assimilation of immigrant-origin ethnic minorities with native-born ethnic majority populations (Duncan and Lieberson 1959; Massey and Denton 1985; Park 1926). Both classical and recent reformulations of assimilation theory conceptualize immigrant incorporation as inherently multidimensional and temporal processes (Alba and Nee 2003; Gordon 1964; Park and Burgess 1921; Portes and Rumbaut 2001). Yet patterns of 'uneven assimilation' is a recurring theme in earlier research on immigrant assimilation (Price 1969: 215-216), which implies immigrant minorities increasingly come to resemble natives in some aspects (e.g., progress in education and the labor market) while ethnic boundaries may remain strong along other dimensions (e.g., spatial segregation and intergroup contact). Nonetheless, the influential spatial assimilation theory asserts increased acculturation and socioeconomic progress to be translated into improved neighborhood attainments across immigrant generations (Massey and Denton 1985; Park 1926).

Contemporary research on immigrant assimilation focuses on patterns of intergenerational mobility in the second generation, where some scholars argue that all immigrant groups will experience gradual progress while others expect disadvantaged groups to fall increasingly behind (Alba, Kasinitz and Waters 2011; Haller, Portes and Lynch 2011). While most of the existing literature focus on socioeconomic outcomes (Drouhot and Nee 2019; Heath, Rothon and Kilpi 2008), we know less about how disadvantaged neighborhood contexts are transmitted from parents to children — often referred to as contextual mobility—and the 
determinants of neighborhood attainment among local-born immigrant descendants. However, recent research from the United States have found that second-generation immigrants experience considerable upward contextual mobility out of deprived childhood neighborhoods (Tran 2020). In contrast, European studies report strong intergenerational reproduction in deprived neighborhood contexts among immigrant populations in France (McAvay 2018), the Netherlands (de Vuijst, van Ham and Kleinhans 2017), the United Kingdom (Zuccotti 2019) and Scandinavia (Gustafsson, Katz and Österberg 2017; Nordvik and Hedman 2019; Van Ham et al. 2014).

Cross-national variation is likely to reflect many factors, but some argue that egalitarian welfare-state institutions and redistributive area-based social policies may counterintuitively slow down the speed of spatial assimilation among immigrants, especially in the Nordic welfare states (Koopmans 2010; Wessel et al. 2017). The key claim is that equalization of neighborhood quality — in terms of local access to decent schools, health care, and other public services — creates a benign opportunity structure where immigrants' incentives for contextual mobility out of disadvantaged residential areas are reduced despite individual socioeconomic progress. Yet, studies of the intergenerational dynamics of spatial assimilation among immigrant descendants have yet to address this argument explicitly.

In this study, we use administrative data to address contextual mobility and neighborhood attainment across immigrant generations in the Norwegian welfare-state setting. Our focus is on two salient neighborhood characteristics—-socioeconomic composition and ethnic segregation - derived from detailed information on residential location in childhood and adulthood, as well as information on the socioeconomic characteristics of individuals as adults and their parents when the individuals were young. First, we describe changes in 
neighborhood contexts from childhood to adulthood among immigrant descendants and natives. Second, we assess the relative importance of group-level differences in individuals' adult socioeconomic attainment, family background, and childhood neighborhood context as drivers behind remaining native-immigrant gaps in adult neighborhood attainments among immigrant descendants.

Our study offers several contributions. To begin, we add to the few prior studies that simultaneously assess intergenerational contextual mobility in both socioeconomic and ethnic neighborhood dimensions (McAvay 2018; Tran 2020; Zuccotti 2019). As such, we also expand prior Norwegian research by exploring both of the abovementioned neighborhood dimensions and by reporting more nuanced variation across immigrant origin groups for additional birth cohorts of immigrant descendants (Nordvik and Hedman 2019).

Our theoretical contribution is addressing the relevance of spatial assimilation theory by exploring whether generous welfare-state policies may slow down the speed of residential integration among immigrant descendants in a Nordic welfare state (Koopmans 2010; Wessel et al. 2017). Norway provides an ideal case for testing this argument since considerable upward socioeconomic mobility has been documented across immigrant generations (Bratsberg, Raaum and Røed 2014; Hermansen 2016, 2017). According to spatial assimilation theory, second-generation socioeconomic progress will lead to improved neighborhood attainments and upward contextual mobility should thus be substantial in the Norwegian context.

The remainder of this paper starts with a discussion of spatial assimilation theory and alternative explanatory theories in the context of an egalitarian Nordic welfare state. Next, we 
discuss previous research and the Norwegian case, before presenting our data and analytical strategy. Finally, we present the results and our concluding discussion.

\section{THEORETICAL FRAMEWORK}

Research on intergenerational mobility addresses persistence in socioeconomic attainmentssuch as education, earnings or occupational class - from parents to their adult children (Black and Devereux 2011; Breen and Jonsson 2005). Following Sharkey (2008), the study of intergenerational contextual mobility extends this focus to address the degree to which neighborhood-level inequalities persist across generations, reflecting both individuals' movement across residential areas and changes in the composition of neighborhoods around non-mobile individuals. To assess neighborhood persistence among second-generation immigrants, it is crucial to assess whether and how the relationship between adult neighborhood attainments and childhood residential location differ by immigrant background (Duncan and Trejo 2015; Heath et al. 2008; White and Glick 2009). A key question relates to so-called locational returns (cf. Logan and Alba 1993), that is whether human capital and socioeconomic progress provide second-generation minorities access to improved neighborhood contexts on par with natives. Below, we outline key theoretical perspectives and empirical predictions.

Spatial assimilation theory projects a tight link between socioeconomic progress and upward neighborhood mobility. Developed within the Chicago school's ecological model of immigrant incorporation, Park (1926: 9) claimed that "change of occupation, personal success or failure [...] tends to be registered in changes of location”. Later research conceptualizes spatial assimilation as driven by two individual-level processes, improved socioeconomic status and acculturation into mainstream culture and language (Alba and Nee 
2003; Logan and Alba 1993; Massey 1985; Massey and Denton 1985). Although access to opportunities found within mainstream society is likely to provide a motivation for living closer to natives, the literature provides more support to the view that declining ethnic segregation is a by-product of minority households seeking to convert gains in human capital and economic resources into higher-quality housing and neighborhoods. Massey (1985: 320), for example, claimed that "[u]pwardly immigrants seek out neighborhoods with better schools, more prestige, and richer amenities, places where natives tend to predominate." Immigrants and their descendants who experience socioeconomic advances may therefore face trade-offs between improved neighborhood quality and continued residence in immigrant-dense areas, often characterized by relative deprivation.

Nonetheless, the standard prediction of spatial assimilation theory is simply that socioeconomic progress across immigrant generations will lead to upward contextual mobility both in terms of improved neighborhood-level socioeconomic status and residential integration with the native-born ethnic majority population. Further, this perspective predicts any remaining immigrant-native gaps in adult neighborhood attainments in large part to reflect differences between immigrant descendants and natives in education and economic resources.

In contrast, alternative explanatory models provide various reasons for why neighborhood disparities may persist across immigrant generations. To begin, the place stratification theory claims that immigrant-origin ethnic minorities face external constraints that sort them into lower-valued segments of the housing market according to their relative standing in society (Charles 2003; Logan and Alba 1993). Influential residents in 'desirable' areas, often members of the native majority, can manipulate space to maintain physical and social 
separation from groups considered less desirable (Johnson, Pais and South 2012). For example, ethnic discrimination in both employment (Birkelund et al. 2019; Quillian et al. 2019) and (rental) housing markets (Andersson, Jakobsson and Kotsadam 2012; Auspurg, Schneck and Hinz 2019) is well-documented. Moreover, natives often move out of or avoid moving into neighborhoods if the local immigrant concentration rises above a given threshold (Aldén, Hammarstedt and Neuman 2015; Crowder, Hall and Tolnay 2011; Wessel and Nordvik 2019).

Further, the ethnic enclave theory argues that immigrant descendants prefer to settle close to other immigrants as adults despite upward socioeconomic mobility (Clark 1992; Logan, Zhang and Alba 2002). Tight-knit immigrant enclaves provide a sense of community and shelter by strengthening shared ethnic identities and in-group solidarity. Immigrant-dense areas can also provide a range of (non-financial) benefits, such as access to ethnic food stores, after-school programs, and other local community institutions, as well as helpful information for minorities navigating the school system and labor market (Xie and Gough 2011; Åslund et al. 2011). Further, adult descendants of immigrants may wish to move closer to their kin in adulthood, for example after they have entered parenthood (Clark, Glick and Bures 2009; Foner and Dreby 2011), which may contribute to persisting ethnic residential segregation across immigrant generations (Brown 2007; Zorlu 2009).

Finally, neighborhood disparities may also persist due to effects of childhood neighborhoods on skill formation, resource accumulation and socialization that are shared by immigrant and native residents (Sharkey and Faber 2014). Spatial variation in school quality and other local institutions, access to adult role models, and the social organization of neighborhood life may affect skill formation and employment-related outcomes, which in turn shape residential 
opportunities (Chetty and Hendren 2018; Vartanian, Buck and Gleason 2007). Childhood neighborhoods may also directly affect parental resource transfers to their children that are linked local housing prices, property wealth, and the inheritance of dwellings (Galster and Wessel 2019). Neighborhood effects may also operate via the transmission of local knowledge and socialization that shape individuals' place attachment and neighborhood stereotyping. Individuals typically become attached to the places where they grew up (Hidalgo and Hernandez 2001) and local place attachment may lead them as adults to return to live close to family, friends, and the areas where they spent their youth (Løken, Lommerud and Lundberg 2013). People may avoid geographic locations where they feel out of place and attach negative neighborhood stereotypes to them, for example due to a relative underrepresentation of people they identify as members of their own group (Ellen 2000).

The behavioral expectation of intergenerational stability in socioeconomic and ethnic neighborhood contexts are similar for both the place stratification and ethnic enclave theories, although the former emphasizes external barriers imposed by natives and the latter stresses the role of in-group residential preferences. An empirical implication of both perspectives is that immigrant-native gaps in adult neighborhood attainments in large part will remain after primarily taking differences in individuals' socioeconomic attainments into account, but also family background and childhood neighborhood context. Similarly, shared neighborhood effects among residents regardless of immigrant background also predicts limited contextual mobility among immigrant descendants. However, if neighborhood effects are similar for immigrant descendants and natives who grew up in the same areas, this perspective also predicts that childhood residential contexts will account for more of the immigrant-native gaps in adult neighborhood attainments. 
From a comparative perspective, recent scholarship have argued that egalitarian welfare-state contexts, such as the Nordic countries, may weaken the relationship between upward socioeconomic mobility and neighborhood attainment (Koopmans 2010; Wessel et al. 2017). Although welfare states may reduce overall levels of ethnic residential segregation by means of taxes, transfers, and public services (Arbaci 2007), the central argument is that equalization in neighborhood quality in welfare state contexts may reduce immigrants' need for upward contextual mobility (Wessel et al. 2017). If so, generous welfare-state policies might slow down the speed of spatial assimilation through a "double compression of differences, first in the system of social stratification and next in the social hierarchy of places" (Wessel et al. 2017: 814).

This implies that a compressed wage structure and redistributive social transfers create low economic inequality (Barth, Moene and Willumsen 2014), which in comparative terms weakens the link between immigrants' earnings level and their purchasing power in the housing market. More importantly, redistributive welfare state policies equalize the quality differences between neighborhoods (Wessel et al. 2017). This means that poor neighborhoods are lifted to higher standards through subsidies, regulations, and various programs for neighborhood planning and regeneration. Area-based redistributive measures are also likely to reduce quality differences between schools and childcare centers, health care, and other public services across different neighborhoods. Consequently, immigrants and their descendants may perceive neighborhoods characterized by relative deprivation as being of an adequate and decent standard in terms of public services, safety and other local amenities.

Given reduced spatial inequality in egalitarian welfare state contexts, immigrants and their descendants may therefore face a reduced trade-off between moving into neighborhoods 
characterized by higher material standards versus continuing to live in immigrant-dense neighborhoods (Wessel et al. 2017). Perhaps counterintuitively, this opportunity structure may lead spatial assimilation to move slower in egalitarian welfare states than in less egalitarian societies, such as the United States, where neighborhood disadvantage and immigrant concentration might be more tightly linked. If higher proximity to natives is primarily a byproduct of improvements in neighborhood quality and material standards (Massey 1985), ethnic segregation may be more persistent if immigrant descendants' incentives to move out of ethnically diverse immigrant-dense areas are weakened in welfare states.

\section{PREVIOUS LITERATURE}

Previous studies from the United States document rigid patterns of neighborhood disadvantage across generations among non-migrant blacks and Hispanic minorities (Britton and Goldsmith 2013; Pais 2017; Sharkey 2008; Swisher, Kuhl and Chavez 2013; Vartanian et al. 2007). Sharkey (2008), for example, found that about $52 \%$ of blacks continued to live in the lowest income quartile of neighborhoods compared to only $7 \%$ among whites. While not taking immigrant generational status fully into account, Swisher et al. (2013) found stronger relationships between neighborhood poverty in adolescence and young adulthood among persons who were black, Mexican or of other Hispanic origins when compared to whites. Adjusting for individuals' adult socioeconomic attainments reduces the minority-majority gap in neighborhood poverty, but the neighborhood attainments of minority members did not yet reach those of the most disadvantaged whites. For Asians, there were no clear gaps in terms of neighborhood poverty relative to whites.

Recently, Tran (2020) found that second-generation immigrants of Chinese, South American, West Indian, and Dominican origin in New York experience contextual mobility into 
neighborhoods characterized by less socioeconomic disadvantage compared to where they lived with their immigrant parents as children. While none of the second-generation groups close the gap in neighborhood attainment relative to whites, all except West Indians fare better than non-migrant blacks and Puerto Ricans. Overall, the US literature suggests that neighborhood inequality is highly rigid within non-migrant ethnoracial minorities while many post-1965 immigrant minorities seem to experience upward contextual mobility.

In Europe, recent studies from France and United Kingdom explore intergenerational change in both neighborhood-level ethnic segregation and socioeconomic composition as well as how patterns vary across several immigrant origin groups (McAvay 2018; Zuccotti 2019). In France, McAvay (2018) found strong neighborhood stability from childhood to adulthood among both immigrants and natives. This pattern is, however, stronger among non-European second-generation immigrants (i.e., African or Asian/Turkish origin). ${ }^{1}$ Intergenerational persistence in the ethnic composition of neighborhoods is also stronger than the corresponding patterns for neighborhood-level unemployment rates. For the UK, Zuccotti (2019) found that that second-generation immigrants — especially those of Pakistani, Bangladeshi, and African background — are more likely than natives to live in immigrantdense and socioeconomically disadvantaged neighborhoods even after accounting for individual socioeconomic resources, family background, and childhood neighborhood characteristics. Interestingly, persistence in ethnic neighborhood composition is stronger among second-generation immigrants than for natives, while such a pattern is less consistent for neighborhood socioeconomic deprivation. Moreover, in both France and the UK characteristics of the childhood neighborhood seem to be more important predictors of

\footnotetext{
${ }^{1}$ However, McAvay (2019) finds that immigrant descendants with high incomes as adults tend to reduce the risk of living in areas with high unemployment rates over time. Similarly, de Vuijst et al. (2017) find that higher education reduces the risk of living in a poor neighborhood among immigrant descendants in the Netherlands, although this risk is still higher than among comparable high-educated natives.
} 
second-generation neighborhood attainment than individual or parental socioeconomic characteristics (McAvay 2018; Zuccotti 2019).

In Scandinavia, Van Ham et al. (2014) found that immigrant descendants have considerably longer cumulative exposure to low-income neighborhoods from childhood into young adulthood, spending almost 3.5 more years in the lowest income quintile over a 18 year period, compared to native Swedes with similar socioeconomic attainments. Similarly, Gustafsson et al. (2017) found that about half of the immigrant descendants from 'visible minorities' in large Swedish metropolitan areas (Stockholm, Gothenburg, and Malmö) grew up in the neighborhood quartile with the lowest mean income and about two-thirds of these continued to live in this quartile as adults. Further, intergenerational correlation in neighborhood-level income composition was about three times stronger than the individuallevel parent-child income correlation. Focusing on Norway's capital city, a prior study also found high intergenerational persistence in neighborhood economic disadvantage among nonEuropean immigrants in the Oslo metropolitan area as almost $40 \%$ of immigrant descendants who grew up in the lowest quartile of the neighborhood income distribution continued to live in this quartile as adults (Nordvik and Hedman 2019).

Despite important contributions in earlier research from Scandinavia, our study contributes by also focusing on both socioeconomic and ethnic dimensions of neighborhood composition and by exploring how contextual mobility varies across different immigrant origin groups. We also provide a systematic assessment of the relative role of individuals' own socioeconomic attainments and their childhood background (i.e., parental resources and neighborhood context) for adult neighborhood attainments. 


\section{IMMIGRATION IN THE NORWEGIAN WELFARE STATE}

The Norwegian context is interesting due to the combination of an ethnically diverse immigrant population, generous and redistributive welfare-state policies, and comparatively low levels of economic inequality. Large-scale immigrant inflows started in the late 1960s with a sizable wave of labor migrants from Pakistan, Turkey, and Morocco. After labor immigration was halted in 1975, a substantial proportion of refugees from conflict areasVietnam, Chile, Sri Lanka, and Iran (1980s), and Balkan, Somalia, and Iraq (1990s)—arrived, in addition to family reunification for the kin of earlier arrived immigrants (Brochmann and Kjeldstadli 2008). By 2020, immigrants and Norwegian-born descendants of immigrants made up $18.2 \%$ of the total population in Norway (Statistics Norway 2020). The relative size of the ethnic diverse Norwegian immigrant population is today comparable to countries such as Sweden, Denmark, Germany, France, and the United Kingdom (OECD 2017). In Norway's capital city, Oslo, non-European immigrants and their descendants make up the majority of residents in many less-advantaged residential areas (Kornstad, Skjerpen and Stambøl 2018).

Immigrants from low-income origin countries often experience low and declining employment rates over the life course (Bratsberg et al. 2014). Due to weak labor market attachment and high numbers of dependent minors, the risk of child poverty is highly elevated within many immigrant minorities (Galloway et al. 2015). Despite disadvantaged childhood origins, many immigrant descendants experience marked upward mobility in the educational system and labor market compared to their parents (Bratsberg et al. 2014; Hermansen 2016; Reisel, Hermansen and Kindt 2019). Children in immigrant households are highly concentrated in immigrant-dense and low-income areas when growing up, but childhood neighborhood segregation appears to be considerably less important than family background for ethnic disparities in education and adult earnings among second-generation immigrants 
(Hermansen 2016; Hermansen and Birkelund 2015). School and neighborhood contexts also seem to be of modest importance for socioeconomic attainment among natives (Hermansen, Borgen and Mastekaasa 2020).

\section{DATA AND MEASURES}

We use administrative data from Norway, where a system of unique personal identifiers for all residents enables us to link individuals to their residential locations and children to their parents. For each year starting in 1990, we observe individuals as nested in their neighborhood of residence. This multilevel structure allows us both to measure aggregate characteristics of all individuals who live in the same neighborhood in a given year and to compare individuals who lived in the same neighborhood during childhood. We use detailed measures of neighborhood context in childhood and adulthood, adult socioeconomic attainments, and family background.

For our purposes, we restrict the sample to all Norwegian-born children with two parents born in Norway and all children of two immigrant parents, who were either born in Norway or immigrated before school-starting age at seven. We select individuals born between 19741988 and who were current residents in 2018. We exclude individuals with 'mixed origin' (i.e., one foreign-born and one Norwegian-born parent). Further, we exclude a small number of individuals with missing information on residential location in childhood and adulthood, or other key child and parental variables.

Finally, we select all individuals of both native and immigrant background living in the top 30 municipalities with the highest share of immigrant descendants at age 16. This is to ensure that our sample is comparable for natives and immigrants in terms of geographic locations in 
childhood. The sample includes Oslo municipality and all large cities in the country. We follow all individuals to the neighborhood contexts where they settle as adults, regardless of whether they moved out of the original municipalities.

Using these sample restrictions, we include about $80 \%$ of the total population of immigrant descendants in Norway in these birth cohorts. This provides an analytic sample of about 314,000 observations. Table 1 presents descriptive statistics separately for all descendants of immigrants $(n=16,345)$ and individuals with Norwegian-born parents $(n=297,471)$.

\section{< Table 1 about here >}

\section{Ethnic Origin}

Our key interest lies in the ethnic origin of the immigrant descendants, defined by parental country of birth. ${ }^{2}$ Those with two Norwegian-born parents are defined as the native majority, while those with two foreign-born parents make up the immigrant descendants. We differentiate between eight regions of origin: West; Eastern Europe; Pakistan; Vietnam; Asia; Middle East; Africa; and South America (Table A1). If the parents have different origin countries, we use the mother's country of birth. ${ }^{3}$

\section{Neighborhood Composition in Childhood and Adulthood}

We measure neighborhoods using Statistics Norway's 'basic statistical unit' classification ('grunnkretser'), which constitute the smallest geographical entities found in Norwegian

\footnotetext{
${ }^{2}$ These categories do not capture ethnicity as such, since this would require detailed information on characteristics such as religion, culture, skin color, and the like, which vary within each of these origin groups. ${ }^{3}$ This follows Statistics Norway's standard classification of country of origin for children of foreign-born parents.
} 
administrative data and are designed to resemble genuine neighborhoods and are relatively homogeneous with respect to the structure of dwellings and their location (for a more thorough description, see Statistics Norway 1999). There are about 13,700 basic statistical units in Norway; on average, about 350 individuals populate each, but this number is substantially higher in populous municipalities.

We measure characteristics of neighborhood contexts in childhood and adulthood in terms of socioeconomic composition and ethnic segregation. Our two measures of the neighborhood composition are aggregated from characteristics of adult residents (18-67 years of age) in the local neighborhood during childhood (mean over ages 13-16) and in adulthood (mean over ages $30-34) .{ }^{4}$ First, we focus on the neighborhood mean annual earnings of adult residents and standardize this as percentile ranks in economic neighborhood composition within each birth cohort. Second, we measure the neighborhood share of native-born adult residents and standardize this as percentile ranks in ethnic neighborhood composition within each birth cohort. For neighborhood composition measured in both childhood and adulthood, this yields a symmetric variable that captures each individual's rank measured as the cohort-specific percentile in the neighborhood distribution in terms of both economic and ethnic composition, ranging from 0.00 (lowest) to 1.00 (highest). By standardizing our measures of neighborhood characteristics, we capture the relative distributional position of each person's residential neighborhood in childhood and adulthood and avoid bias related to secular trends of earnings growth, economic conjunctures, and increasing immigrant-origin population shares during the period of measurement (i.e., 1990 through 2018). ${ }^{5}$

\footnotetext{
${ }^{4}$ For the oldest and youngest birth cohorts not observed for all years, we only average across the observed years (e.g., we only use information from age 16 for individuals born in 1974, for ages 15 and 16 for those born in 1975, etc., and from age 30 for individuals born in 1988, for ages 30 and 31 for those born in 1987, etc.)

${ }^{5}$ Appendix Figures A1 and A2 show the untransformed distributions of economic and ethnic neighborhood contexts in childhood and adulthood.
} 
To gauge the role of childhood residential segregation further, we also include fixed effects (i.e., dummy variables) for either municipality or neighborhood of residence (measured at age 16) in the multivariate analysis. This enables us to restrict the comparison only to individuals who grew up in the same municipality or neighborhood, thus controlling for all shared timeinvariant factors shared between youth who lived in the same geographic unit. During our observation period, there were about 430 municipalities in Norway.

\section{Children's Socioeconomic Attainments and Family Background}

To capture individual and parental socioeconomic characteristics, we use information on completed education and annual earnings. ${ }^{6}$ Child education refers to the highest level of education at age 30 with four different attainment levels. Parental education refers to the attainment level of the parent with highest level of education when the child was 16 years old using the same classification. ${ }^{7}$

Child earnings refer to pre-tax annual earnings from gainful employment (including income from self-employment; capital income and social welfare transfers are not included). This information emanates from tax records on annual gross income subject to taxation, captured with high accuracy. ${ }^{8}$ We measure annual earnings (including zero earnings) when the child was 30 years old. We rank children based on their earnings relative to other children in the same birth cohort, irrespective of gender. Parental earnings measure pre-tax annual earnings and income from self-employment. First, we average each parent's pre-tax annual earnings

\footnotetext{
${ }^{6}$ All parental measures refers to the biological mother and father, as registered in the Central Population Register.

${ }^{7}$ Because immigrant descendants are overrepresented among those who lack information on parental education, we also include a separate indicator for this category.

${ }^{8}$ All earnings in Norwegian kroner (NOK) are inflated to 2018 levels using the Norwegian consumer price index.
} 
over the years the child was aged 13-20, including zero earnings. Second, we summarize both parents' average earnings over this period and we rank parents' earnings relative to other parents with children in the same birth cohort, irrespective of the child's gender. For both children's and their parents' earnings, these symmetric variables measure the cohort-specific percentile rank in the earnings distribution, ranging from 0.00 (lowest) to 1.00 (highest).

Finally, we include measures of birth cohort, child gender, whether the child was the firstborn child of his or her mother, number of siblings, mother's age at birth, and a measure of whether the child lived in an intact or reconstituted family at age 16 (i.e., a household with two adults that were either married or had common children).

\section{METHODS}

The first aim of our analysis is to describe patterns of contextual mobility from immigrant parents (i.e., neighborhood rank in childhood) to their second-generation children (i.e., neighborhood rank in adulthood) in terms of both neighborhood socioeconomic composition and ethnic segregation. To achieve this, our primary approach is to regress individual's adult neighborhood rank on their childhood neighborhood rank. In a standard regression to the mean framework (Duncan and Trejo 2015; Dustmann and Glitz 2011), the bivariate association between child and the parental variables describes how strongly these are correlated (i.e., in our case the neighborhood rank in childhood and adulthood, cf. McAvay 2018; Sharkey 2008). If the slope equals one, this implies that the relative position in the distribution of neighborhood contexts in childhood and adulthood is identical within a given population group (Dustmann and Glitz 2011: 399-401). ${ }^{9}$

\footnotetext{
${ }^{9}$ Note that when comparing intergenerational mobility across different population groups (e.g., between natives and immigrant groups from different regions of origin), movement towards intergenerational convergence between two groups in the distribution of a given outcome (e.g., neighborhood rank or earnings) is also determined by the group-specific intercepts in the model. This implies that if group-specific intercepts differ
} 
If plotted visually, perfect intergenerational stability in neighborhood rank implies that observations lie at the diagonal when the neighborhood position in childhood and adulthood is compared (i.e., the neighborhood rank is the same for both measures). To assess non-linearity, we plot the mean neighborhood rank in adulthood within each neighborhood percentile rank in childhood for immigrants and natives separately. This allows us to see whether nativeimmigrant differences in intergenerational neighborhood persistence are stronger among those who grew up in the most economically disadvantaged or immigrant-dense neighborhoods.

We also report results from transition matrices where mobility is described as immigrantnative differentials in the probability of moving from one point in the distribution of neighborhoods to another (McAvay 2018; Sharkey 2008). Transition matrices provide direct evidence on how contextual mobility varies across the neighborhood distribution, by describing the probability that natives and immigrant descendants who lived in a given neighborhood quartile in childhood end up in a given destination quartile as adults (i.e., outflow rates from childhood neighborhood quartiles).

In sum, these descriptive analyses allow us to assess whether intergenerational contextual mobility among immigrant descendants follows the predictions of spatial assimilation theory (i.e., marked reductions in immigrant-native gaps in neighborhood attainments). By contrast, patterns of intergenerational stability relative to natives would be in line with place stratification theory, ethnic enclave theory, and related perspectives. 
Our second aim is to use multivariate ordinary least squares (OLS) regression to assess the contribution of different factors to patterns of contextual mobility and neighborhood attainment among immigrants and natives. We start by exploring to what extent the bivariate association between neighborhood rank in childhood and adulthood for natives and immigrant descendants reflects (1) regional variation (i.e., childhood municipality fixed effects), (2) individual socioeconomic attainments, and (3) family background characteristics. Thus, we are able to break down the original correlation to identify the relative importance of each of these factors for intergenerational neighborhood persistence (cf. McAvay 2018; Sharkey 2008).

Building on Logan and Alba's (1993) locational attainment model, our final set of analyses assesses how the remaining native-immigrant gaps in adult neighborhood attainment reflect the relative contribution of group-level differences in (1) childhood municipality, socioeconomic characteristics of (2) individuals and (3) their parents, and (4) childhood neighborhood contexts. In addition to observed neighborhood characteristics in childhood, we include neighborhood fixed effects that capture all stable contextual factors shared among neighbors through the statistical comparison of immigrant descendants and natives who grew up in the same neighborhood (Hermansen 2016).

Overall, the multivariate analyses allow us to assess the contribution of individuals' own socioeconomic attainments relative to parental resources and childhood residential context with respect to (1) intergenerational neighborhood persistence and (2) remaining nativeimmigrant gaps in adult neighborhood attainment. From the spatial assimilation perspective, the key prediction is that own socioeconomic attainments should be central in accounting for both patterns while family background and childhood residential contexts should matter less. 
If intergenerational persistence and adult neighborhood gaps remain net of all controls, this lends more supports to theoretical perspectives that emphasize on immigrant descendants' ingroup preferences for (co-ethnic) immigrant neighbors (i.e., ethnic enclave theory) or external constraints in the housing market (i.e., place stratification theory).

\section{RESULTS}

\section{Patterns of Intergenerational Contextual Mobility among Immigrants and Natives}

We start by describing overall intergenerational change in neighborhood context across immigrant generations. Figure 1 documents overall change in the quartile distributions in childhood and adulthood for economic (panels A and B) and ethnic (panels C and D) neighborhood ranks among immigrant descendants as a whole, which reveals two striking findings. First, there is a high overrepresentation of immigrant descendants among those in the bottom childhood quartile in terms of both neighborhood economic and ethnic rank. While $36.6 \%$ of immigrant descendants grew up in the neighborhood quartile with the lowest earnings, $75.6 \%$ where in the neighborhood quartile with the lowest share of native residents in childhood. Second, these native-immigrant gaps in neighborhoods contexts persist in adulthood. As adults, $41.3 \%$ of all immigrant descendants are in the bottom quartile of the neighborhood economic distribution. This is a higher share than in childhood but note that the distribution across the other quartiles is slightly closer to the natives. For ethnic neighborhood distribution, the corresponding figure is $63.7 \%$. The pattern is one of high intergenerational stability in neighborhood context, but a key question is whether this pattern varies across second-generation minorities from different regions of origin.

\section{< Figure 1 about here >}


Figure 2 describes the mean economic (panel A) and ethnic (panel B) neighborhood rank in childhood and adulthood for each origin group among immigrants and the natives. Each circle represents an origin group and indicates the degree of intergenerational change in relative rank in the neighborhood distributions from childhood to adulthood. Each circle's center refers to the mean neighborhood rank in childhood plotted against the corresponding rank in adulthood for each origin group and the size of each circle is proportional to the number of observations within each origin group. For reference purposes, the black cross represents the corresponding childhood-adulthood mean for the native population. Finally, the grey line along the diagonal in both panels of each figure refers to a hypothetical origin-destination slope where immigrant descendants in adulthood completely reproduce the neighborhood rank of the neighborhood in which they grew up (i.e., the origin-destination slope equals 1). This provides a useful benchmark for the level of intergenerational contextual mobility, as origin region circles above the diagonal imply upward mobility in neighborhood rank while observations below the diagonal implies downward mobility. ${ }^{10}$

\section{< Figure 2 about here >}

In Figure 2, panel A documents a relative persistence in neighborhood economic rank from childhood to adulthood within most origin groups. First, all groups except descendants of Pakistani and African immigrants are located above or close to the diagonal which implies that most second-generation minorities either slightly improve their economic neighborhood rank as adults or stay in neighborhoods similar to those they grew up in. Second, the South American and Vietnamese origin groups experience the most pronounced pattern of upward mobility with an improvement in economic neighborhood rank of about 10 percentiles. In

\footnotetext{
${ }^{10}$ Detailed figures for change in the distribution of economic and neighborhood quartiles in childhood and adulthood are reported in Appendix Table A2.
} 
absolute terms, the Western group has the highest economic neighborhood rank in both childhood and adulthood.

In panel B, we present results for change in neighborhood rank from childhood to adulthood in terms of ethnic neighborhood rank. We find a slightly different pattern here, as immigrant descendants in all origin groups as adults have moved up from the diagonal compared to their childhood ethnic neighborhood rank, and this upward mobility is most pronounced in the South American group. This implies that the immigrant descendants, as adults, settle in neighborhoods with a slightly higher relative presence of native-born adult residents in the overall neighborhood distribution. Relative to their economic neighborhood rank, however, the immigrant descendants are clustered in neighborhoods with lower ethnic neighborhood ranks as adults and this is particularly so for the Pakistani, Middle Eastern, and African origin groups.

Figure 3 reveals how intergenerational neighborhood persistence varies between natives and immigrant descendants across the childhood neighborhood distribution. We plot the binned mean adulthood neighborhood rank within each percentile of the childhood neighborhood distribution for immigrant descendants, as a whole, and native Norwegians, separately. Further, the solid and dashed lines plot the linear slope for the bivariate association between neighborhood rank in childhood and adulthood separately for immigrants and natives. The linear childhood-adulthood slopes highlight the central tendencies in the degree of intergenerational persistence in neighborhood context among immigrant descendants and natives, while the non-parametric binned percentile plots allow us to assess non-linear deviations from the overall association in different parts of the distribution of childhood neighborhood contexts. 


\section{$<$ Figure 3 about here >}

Panel A shows a relatively strong linear and parallel relationship between economic neighborhood rank in childhood and adulthood among immigrant descendants (slope $=0.367$, intercept $=0.247)$ and natives $($ slope $=0.439$, intercept $=0.275)$. Compared to natives, immigrant descendants on average settle in neighborhoods with slightly lower economic ranks as adults. ${ }^{11}$

Turning to ethnic neighborhood rank, panel B reveals that the association between neighborhood rank in childhood and adulthood is about two-thirds stronger among immigrant descendants $($ slope $=0.480$, intercept $=0.148)$ compared to natives $($ slope $=0.287$, intercept $=$ 0.346). Higher intergenerational persistence among immigrant descendants implies that the native-immigrant gaps in adult neighborhood ethnic rank are considerably larger among individuals who grew up in the most immigrant-dense neighborhoods. ${ }^{12}$ Correspondingly, the binned percentile plot shows a stronger tendency of adult reproduction of childhood neighborhood rank among immigrant descendants who grew up in neighborhoods with high immigrant concentrations, while their native counterparts from similar neighborhood origins tend to settle in areas with considerably higher shares of native-born adult residents (i.e., ethnic neighborhood ranks). Native-immigrant gaps are smaller among individuals who grew up in less-immigrant dense neighborhoods (i.e., higher childhood ethnic neighborhood rank),

\footnotetext{
${ }^{11}$ The estimated adult immigrant-native gaps in economic neighborhood rank range between 3 and 6 percentiles for those from the bottom half of the childhood neighborhood distribution.

12 The estimated adult immigrant-native gaps in ethnic neighborhood rank range between 20 and 10 percentiles for those from the bottom half of the childhood neighborhood distribution.
} 
but these immigrant descendants also have a stronger tendency to settle in more immigrantdense neighborhoods compared to natives with childhood neighborhood origins.

Figure 4 presents transition matrices on how mobility varies across the distribution of childhood neighborhood quartiles for native and the different immigrant origin groups in terms of economic (panel A) and ethnic (panel B) neighborhood composition (i.e., outflow rates as the distribution of individuals by their adult neighborhood quartiles given their childhood neighborhood quartile separately by origin group). As immigrant descendants are strongly overrepresented among those growing up in neighborhoods with the lowest average earnings and lowest share of native-origin adult residents (cf. Figure 1 and Appendix Table A2), we primarily focus on outflow from the lowest neighborhood quartile (i.e., $<25$ th). We compare this to the outflow rates from the other childhood neighborhood quartiles (i.e., 2550th, 50-75th, and $>75$ th). For natives and the immigrant descendants, the rows refer to the different neighborhood origin quartiles and the four blocks within each row refer to destination neighborhood quartiles in adulthood. Thus, we compare immigrant origin groups and natives in terms of adult movement out of the bottom neighborhood quartile, and movement into the bottom quartiles for individuals who grew up in other parts of the neighborhood distribution.

\section{< Figure 4 about here >}

Panel A shows that descendants of immigrants from Pakistan (61\%), the Middle East (60\%), and Africa (58\%) who grew up in the bottom economic neighborhood quartile have a higher likelihood of staying in a neighborhood context in the bottom quartile as adults compared to natives $(44 \%)$. For individuals who grew up in the other neighborhood quartiles, these three 
origin groups also have markedly higher shares living in the bottom quartile as adults compared to natives. For immigrant descendants from the remaining origin regions (i.e., West, Eastern Europe, Vietnam, Asia, and South America) the outflow rates in terms of neighborhood economic composition are not that different from those of their native Norwegian peers and ranges between 40\% (Vietnam) and 51\% (Eastern Europe). These origin groups, however, have slightly higher probabilities of moving into the bottom neighborhood quartile from other parts of the distribution as adults.

Turning to ethnic composition, panel B shows that immigrant descendants from all origin regions - although most pronounced for the Pakistani, Middle Eastern, and African groupsare strongly overrepresented among those who both grew up in and, as adults, settle in neighborhood contexts with the lowest share of native-origin adult residents. Among natives, $34 \%$ of those who grew up in the bottom quartile also settle in this quartile as adults while the figure ranges from a low of about 50\% (West and South America) to the highest levels among the Pakistani (82\%), African (79\%), and the Middle Eastern (73\%) origin groups. For immigrant descendants who did not grow up in the bottom neighborhood quartile, all origin groups are more likely to settle in the bottom neighborhood quartile as adults compared to natives and this tendency is, again, strongest for the descendants of Pakistani, African, and the Middle Eastern immigrants.

Overall, our results reveal a high degree of intergenerational neighborhood stability among the immigrants who grew up in the most economically disadvantaged and immigrant-dense neighborhoods. Importantly, we also find that immigrant descendants who grew up in less immigrant-dense neighborhoods (i.e., quartiles 25-50th, 50-75th, and $>75$ th) are also 
considerably more likely to move into neighborhoods with the highest immigrant concentrations as adults (i.e., downward mobility in terms of ethnic neighborhood quartile).

To put these results into context, we find that the share who remain in the bottom quartile of the economic neighborhood distribution among natives (about 40\%) is comparable to studies from Sweden (Gustafsson et al. 2017) and France (McAvay 2018), as well as for nonHispanic whites in the US (Sharkey 2008). For descendants of immigrants from Pakistan, the Middle East, and Africa in Norway, about $60 \%$ of those from the bottom economic quartile remain there as adults (Figure 4, panel A), which is higher than that found among descendants of African (54\%) and Asian/Turkish (47\%) immigrants in in France (McAvay 2018). Gustafsson et al. (2017) report that $61 \%$ of immigrant descendants from 'visible minorities' (i.e., Africa, Asia, Latin America, and Southern Europe) in Sweden remain in the bottom economic neighborhood quartile, which is comparable to our findings.

In terms of ethnic neighborhood segregation, we find that about $30 \%$ of natives from the most immigrant-dense childhood neighborhood quartile remain there as adults, while the corresponding number in France is 42\% (McAvay 2018). Compared to our estimates for the Pakistani, African, and Middle Eastern origin groups (Figure 4, panel B), McAvay (2018) reports lower figures for descendants of Asian/Turkish immigrants (69\%), African (63\%), and Southern European (48\%) immigrants in France, and the gaps relative to natives are larger. The results of Tran (2020) are not directly comparable, but the study reports that secondgeneration immigrants in the United States experience significantly higher rates of upward contextual mobility relative to non-migrant blacks although they have yet to reach parity with non-Hispanic whites. ${ }^{13}$ Overall, this suggests that the level of intergenerational stability of

\footnotetext{
${ }^{13}$ Sharkey (2008) reports that $72 \%$ of non-migrant black Americans remain in the bottom economic neighborhood quartile in the United States.
} 
living in low-income and immigrant-dense neighborhoods among immigrant descendants is comparable to or lower than those reported for Sweden, France, and the United States (Gustafsson et al. 2017; McAvay 2018; Tran 2020).

\section{Assessing Drivers behind Contextual Mobility and Neighborhood Attainment}

In the multivariate analyses, we start by assessing to what extent childhood municipality as well as individual and parental socioeconomic characteristics account for why immigrant descendants and natives as adults often remain in neighborhood contexts similar to where they grew up. Table 2 returns to the bivariate neighborhood rank-rank slopes for each neighborhood dimension estimated separately for immigrants and natives (cf. Figure 3). Using OLS regression, we compare the bivariate coefficient to the coefficients estimated after sequentially adding controls for childhood municipality fixed effects and individuals own and parental socioeconomic characteristics.

\section{< Table 2 about here>}

Panel A reports the results for economic neighborhood rank. Adding controls for municipality fixed effects reduces the coefficients with $33.3 \%$ for natives and $19.1 \%$ for immigrant descendants. For natives, including additional controls for individual and parental socioeconomic characteristics separately or both combined reduces the coefficients relative to the baseline estimate further to $45.3 \%, 47.4 \%$, and $51.0 \%$, respectively. The corresponding reductions are $27.5 \%, 31.1 \%$, and $34.6 \%$ among immigrant descendants. Turning to Panel $\mathrm{B}$, introducing controls for municipality fixed effects reduces the coefficients for ethnic neighborhood rank by $56.4 \%$ for natives and $50.8 \%$ for immigrant descendants. For natives, adding separate controls for individual (55.4\%) and parental (55.1\%) characteristics, or both 
simultaneously (55.4\%), do not reduce the gaps any further relative to the baseline. By contrast, controls for individual (52.9\%) and parental (58.5\%) characteristics separately or combined $(59.2 \%)$ reduce the coefficients slightly more among immigrant descendants.

For both natives and immigrant descendants, these results suggest that socioeconomic characteristics of the adult individuals, followed by parental characteristics, are of relatively modest importance in accounting for the intergenerational continuity in neighborhood rank both in terms local economic and ethnic composition. However, continuity in neighborhood environment from childhood to adulthood, especially in terms of ethnic neighborhood composition, is more strongly related to the municipality where they grew up. For both neighborhood dimensions, introduction of these controls reduces the baseline association to a higher degree among immigrant descendants than natives. Nevertheless, the intergenerational correlation in both dimensions of neighborhood environment remains strong for both immigrant descendants and natives after inclusion of this broad set of controls. While not probing immigrant-native differences in France, McAvay (2018) also found that the broader geographical context - measured by municipality fixed effects - account for more of the association between both economic and ethnic neighborhood composition in childhood and adulthood compared to socioeconomic characteristics of both the adult individuals and their parents.

In our final set of analyses, we shift focus to the relative role of individual socioeconomic attainment, family background, and childhood residential location in accounting for remaining gaps in neighborhood attainment between natives and the various origin groups among the immigrant descendants. Figure 5 summarizes the estimated native-immigrant gaps in adult economic (panel A) and ethnic (panel B) neighborhood rank for each origin group from a 
series of OLS regressions. In each panel, we first present baseline native-immigrant gaps before (model 1) and after (model 2) adjusting for municipality fixed effects. Then, we present estimated gaps in models that separately control for socioeconomic characteristics of the adult individuals (model 3) and their parents (model 4), as well as observed characteristics and fixed effects for childhood neighborhoods (model 5). Finally, we control for all child, parental, and childhood neighborhood characteristics simultaneously (model 6). See the figure, for a more detailed description of the different model specifications.

\section{< Figure 5 about here >}

Panel A shows that the baseline native-immigrant gaps (model 1) in neighborhood economic rank are in line with the results reported earlier and the largest gaps are found among the Pakistani, Middle Eastern, and African origin groups. There is no baseline gap for the Western group, while the Vietnamese, Asian, South American, and Eastern European groups are comparable in the middle. Adjusting for childhood municipality increases gaps slightly for some groups (model 2). Further, adding controls for individual socioeconomic attainments (model 3) is of relatively limited importance, while family background tends to matter slightly more (model 4), and controlling for childhood neighborhood context generally reduces the estimated gaps the most (model 5). Net of all controls combined (model 6), we account for between 41-61\% of the baseline gaps for the Pakistani, Middle Eastern, and the African groups. For the Vietnamese, South American, and Western origin groups, the gaps are entirely closed after including all controls, while a conditional gap of less than five percentiles remains in the Eastern European and the Asian group. 
Panel B reveals a slightly different pattern for native-immigrant gaps in neighborhood ethnic rank. The baseline gaps in ethnic neighborhood rank are generally larger (model 1), but the variation between origin groups is similar to that found for neighborhood economic rank. There is also a moderate gap for the Western origin group, comparable to that found among descendants of South American immigrants. Adding controls for municipality fixed effects to the baseline model (model 2) reduces the gaps for all origin groups - which is likely due to immigrant descendants generally living in municipalities with higher shares of immigrant residents. However, adding controls for socioeconomic characteristics of adult individuals (model 3) or their family background (model 4) tends not to reduce the estimated gaps, and for some groups reveal larger net gaps. However, controlling for childhood neighborhood context (model 5) is related to a relatively small reduction in the estimated gaps for all origin groups compared to the results for economic neighborhood rank, and the gap net of all controls together is very similar (model 6). The full set of controls reduces the estimated native-immigrant gaps between 40-46\% for Pakistani, Middle Eastern, and African immigrant descendants. The baseline gaps are smaller for the other origin groups, but the reductions range between 23\% (Vietnam) and 52\% (Western). However, there are remaining, and often large, gaps in ethnic neighborhood rank for all origin groups.

To sum up, these results show that immigrant descendants often settle in neighborhoods with similar socioeconomic profiles when compared to native peers who are comparable in terms of adult attainments, family background, and childhood neighborhood contexts. However, there are remaining gaps for the descendants of Pakistani, Middle Eastern, and African immigrants. Relative to these very same native peers, immigrant descendants from all origin groups nevertheless tend to live in neighborhoods with considerably lower shares of nativeborn residents as adults. Finally, childhood residential segregation and, for neighborhood 
socioeconomic composition, family background are more important than individuals' own socioeconomic attainment as factors accounting for native-immigrant gaps in neighborhood attainments. Similarly, research from France (McAvay 2018), the United Kingdom (Zuccotti 2019), and the United States (Tran 2020) also find that childhood neighborhood context matter more than parental or own adult socioeconomic status for minority-majority gaps in socioeconomic neighborhood attainments. In terms of ethnic neighborhood segregation, these studies report childhood neighborhood context to be the most important factor and that remaining immigrant-native neighborhood gaps net of controls tend to be larger for ethnic neighborhood composition than for socioeconomic neighborhood composition. These patterns resemble those we document for Norway.

\section{DISCUSSION AND CONCLUSIONS}

This study has addressed intergenerational transmission of neighborhood context — in terms of economic composition and ethnic segregation —-from immigrant parents to their adult secondgeneration children using rich administrative data from the Norwegian welfare-state setting. We find that many immigrant descendants of non-European ancestry who grew up in neighborhood contexts characterized by relative economic deprivation and comparatively few native-origin residents tend to settle in similar contexts as adults. The immigrant-native gaps in adult neighborhood attainment are largest in terms of ethnic neighborhood composition, especially for immigrant descendants who grew up in the most immigrant-dense neighborhoods. Adult second-generation immigrants' overrepresentation in low-income and immigrant-dense areas as adults reflects both higher immobility relative to natives and higher inflow into such areas from other parts of the neighborhood distributions. Yet, there is considerable variation across non-European origin groups, as immigrant descendants from Vietnam and other Asian countries, South America, and Eastern Europe tend to live in 
neighborhoods characterized by less economic disadvantage and higher proximity to the native majority as adults. In contrast, second-generation immigrants of Pakistani, African, and the Middle Easter origin experience the most pronounced pattern of intergenerational persistence in low-income and immigrant-dense neighborhood contexts.

Our first key finding is that the limited degree of intergenerational contextual mobility point to a continued salience of ethnic origin for spatial inequality among immigrant descendants in Norway. Given the high level of socioeconomic progress observed among non-European immigrant descendants in Norway (Bratsberg et al. 2014; Hermansen 2016), this largely contradicts the standard predictions of spatial assimilation theory-which holds that acculturation and socioeconomic gains will translate into improved neighborhood attainments. For the most disadvantaged immigrant minorities, intergenerational contextual immobility in the most economically disadvantaged and immigrant-dense neighborhoods is similar to or higher than that reported in Sweden, France, and the United States (Gustafsson et al. 2017; McAvay 2018; Tran 2020).

Our second key finding is that marked socioeconomic progress can take place without a corresponding movement toward spatial assimilation. While net differences in adult immigrant-native gaps in ethnic neighborhood segregation were considerably larger than neighborhood socioeconomic composition from most origin groups, our results show that childhood residential segregation is considerably more important than both individuals' own socioeconomic attainments and family background. We also capture any unobserved characteristics of local areas shared by neighboring children, such as housing prices, the quality of local schools or formation of preferences for the residential environment experienced in childhood by exploiting neighborhood fixed effects. This is in line with recent 
studies that point to the broader geographic context in childhood as a central observed factor shaping the neighborhood attainments of immigrant descendants (McAvay 2018; Zuccotti 2019). Since research from Norway have found residential segregation to be less important for immigrant-native gaps in socioeconomic attainments (Hermansen 2016), our finding of a more pronounced role of childhood geographic context for neighborhood outcomes could therefore reflect socialization processes related to place attachment and neighborhood stereotyping.

Importantly, the fact that differences between immigrant descendants and natives in adult socioeconomic attainments is the least important factor in accounting for the remaining gaps in adult neighborhood attainments, suggests that other behavioral mechanisms must be behind these patterns. This further raises the question of whether the relative lack of spatial assimilation reflects external constraints in the housing market or persist in-group preferences of (co-ethnic) immigrant neighbors.

Several mechanisms may help account for the limited contextual mobility observed among immigrant descendants. However, limited contextual mobility and persistent immigrant-native gaps in neighborhood attainment is consistent with the expectation that spatial equalization across residential areas might weaken incentives to move out of immigrant dense and lowincome neighborhoods among socioeconomically upwardly mobile immigrants and their descendants in Norway (Wessel et al. 2017). As immigrant-native gaps in labor market earnings have been reduced by about three-fourths from immigrant parents to their adult native-born children (Hermansen 2016), it seems reasonable to expect that spatial assimilation should have been stronger here than in many other immigrant-receiving Western countries. 
Persistent neighborhood segregation despite strong individual socioeconomic progress may therefore reflect an increased scope for in-group residential preferences in the egalitarian Norwegian welfare-state setting. If the choice of adult residential location is primarily driven by place attachment and preferences for (co-ethnic) immigrant neighbors, this could explain the limited degree of contextual mobility among immigrant descendants. The ethnic enclave perspective argues that living close to (co-ethnic) immigrants may provide access to networks important for jobs, housing, and other nonpecuniary community resources (Clark 1992; Logan et al. 2002). Research from Scandinavia has found that immigrants may benefit economically from living close to other immigrants and that proximity to co-ethnics matter for immigrants' settlement patterns (Aradhya et al. 2017; Godøy 2017; Åslund et al. 2011).

Nonetheless, it is also likely that immigrant descendants' continued overrepresentation in immigrant-dense and economically disadvantaged neighborhoods in part also reflects external barriers in the housing market. Previous studies from Norway show that natives living in immigrant-dense areas both report a wish to reduce local immigrant concentration and are prone to move out of such neighborhoods (Andersson, Brattbakk and Vaattovaara 2017; Wessel and Nordvik 2019). Further, research has documented ethnic discrimination in the Norwegian rental housing market (Andersson et al. 2012). Moreover, the role of external barriers - as well as in-group preferences - may also differ across immigrant minorities. For example, survey data show that descendants of Pakistani immigrants report having experienced discrimination in education, work, and the public sphere to a considerably higher degree than more successful second-generation minorities, such as descendants of Vietnamese immigrants (Dalgard 2018). 
While these explanations may seem as competing, such processes could also be selfreinforcing and complementary (e.g., anti-immigrant hostility in the majority may strengthen ethnic homophily in residential choice among minorities). As such, lack of spatial assimilation despite socioeconomic progress highlights the difficulty of separating opportunity barriers from preferences when making inferences about 'equality of opportunity' in observational studies on intergenerational mobility more generally (Swift 2004). This also points to a complex character of 'uneven assimilation' (Price 1969), where immigrant incorporation across different social, cultural, and structural dimensions is not bound to move in tandem (Alba and Nee 2003; Gordon 1964).

Our study has some limitations that future research should address. To begin, we measure neighborhood attainments early in adulthood and this may affect estimated native-immigrant neighborhood gaps. While life-course dynamics could lead to reduced differences between immigrant-origin and native-origin individuals (McAvay 2018; South et al. 2016), early-adult neighborhood attainment gaps could also widen as immigrant descendants and natives embark on different housing trajectories. Moreover, research shows that young adults of native Norwegian origin often move closer to their parents after entering parenthood (Løken et al. 2013). For immigrant descendants, a similar behavior would contribute to reproducing patterns of ethnic segregation and lead to so-called 'delayed spatial assimilation' if immigrant descendants continue to stay close to their kin due to cultural expectations or family obligations (Brown 2007; Zorlu 2009). Future research would benefit from exploring in more detail how kinship-based and co-ethnic networks influence residential location decisions among immigrant descendants. The limited spatial assimilation observed among immigrant descendants also provides fertile ground for future qualitative and survey-based research that 
can provide self-reported information on individuals' experiences, preferences, and opportunities.

To conclude, we find a high degree of intergenerational persistence in socioeconomic neighborhood disadvantage and ethnic segregation among immigrant descendants. The relative absence of spatial assimilation is particularly interesting given the high degree of upward socioeconomic mobility documented within the same second-generation immigrant minorities in Norway (Hermansen 2016). As such, this indicates that socio-spatial disadvantage and relative isolation from ethnic mainstream neighborhoods may be more durable than socioeconomic disadvantage within contemporary immigrant-origin ethnic minorities. In particular, testing the institutional argument that equalization of neighborhood quality in egalitarian welfare states slows down spatial assimilation across immigrant generations should be a key task for future comparative research.

\section{REFERENCES}

Alba, R.and N. Foner. 2015. Strangers No More: Immigration and the Challenges of Integration in North America and Western Europe. Princeton: Princeton University Press.

Alba, R., P. Kasinitz, and M.C. Waters. 2011. "The Kids Are (Mostly) Alright: SecondGeneration Assimilation." Social Forces 89(3):763-773.

Alba, R.and V. Nee. 2003. Remaking the American Mainstream: Assimilation and Contemporary Immigration. Cambridge, MA: Harvard University Press.

Aldén, L., M. Hammarstedt, and E. Neuman. 2015. "Ethnic Segregation, Tipping Behavior, and Native Residential Mobility." International Migration Review 49(1):36-69.

Andersson, L., N. Jakobsson, and A. Kotsadam. 2012. "A Field Experiment of Discrimination in the Norwegian Housing Market: Gender, Class, and Ethnicity." Land Economics 88(2):233-240.

Andersson, R., I. Brattbakk, and M. Vaattovaara. 2017. "Natives' opinions on ethnic residential segregation and neighbourhood diversity in Helsinki, Oslo and Stockholm." Housing Studies 32(4):491-516. 
Aradhya, S., F. Hedefalk, J. Helgertz, and K. Scott. 2017. "Region of Origin: Settlement Decisions of Turkish and Iranian Immigrants in Sweden, 1968-2001." Population, Space and Place 23(4):e2031.

Arbaci, S. 2007. "Ethnic segregation, housing systems and welfare regimes in Europe." European Journal of Housing Policy 7(4):401-433.

Auspurg, K., A. Schneck, and T. Hinz. 2019. "Closed doors everywhere? A meta-analysis of field experiments on ethnic discrimination in rental housing markets." Journal of Ethnic and Migration Studies 45(1):95-114.

Barth, E., K.O. Moene, and F. Willumsen. 2014. "The Scandinavian model—An interpretation." Journal of Public Economics 117:60-72.

Birkelund, G.E., T.W. Chan, E. Ugreninov, A.H. Midtbøen, and J. Rogstad. 2019. "Do terrorist attacks affect ethnic discrimination in the labour market? Evidence from two randomized field experiments." British Journal of Sociology 70(1):241-260.

Black, S.E.and P.J. Devereux. 2011. "Recent developments in intergenerational mobility." Handbook of labor economics 4:1487-1541.

Bratsberg, B., O. Raaum, and K. Røed. 2014. "Immigrants, Labour Market Performance and Social Insurance." Economic Journal 124(580):F644-F683.

Breen, R.and J.O. Jonsson. 2005. "Inequality of Opportunity in Comparative Perspective: Recent Research on Educational Attainment and Social Mobility." Annual Review of Sociology 31:223-243.

Britton, M.L.and P.R. Goldsmith. 2013. "Keeping People in Their Place? Young-Adult Mobility and Persistence of Residential Segregation in US Metropolitan Areas." Urban Affairs 50(14):2886-2903.

Brochmann, G.and K. Kjeldstadli. 2008. A History of Immigration: The Case of Norway, 9002000. Oslo: Universitetsforlaget.

Brown, S.K. 2007. "Delayed spatial assimilation: Multigenerational incorporation of the Mexican-origin population in Los Angeles." City Community 6(3):193-209.

Charles, C.Z. 2003. "The Dynamics of Racial Residential Segregation." Annual Review of Sociology 29(1):167-207.

Chetty, R.and N. Hendren. 2018. "The impacts of neighborhoods on intergenerational mobility I: Childhood exposure effects." Quarterly Journal of Economics 133(3):1107-1162.

Clark, R.L., J.E. Glick, and R.M. Bures. 2009. "Immigrant Families Over the Life Course: Research Directions and Needs." Journal of Family Issues 30(6):852-872.

Clark, W.A. 1992. "Residential preferences and residential choices in a multiethnic context." Demography 29(3):451-466.

Crowder, K., M. Hall, and S.E. Tolnay. 2011. "Neighborhood Immigration and Native OutMigration." American Sociological Review 76(1):25-47. 
Dalgard, A.B. 2018. "Levekår blant norskfødte med innvandrerforeldre i Norge 2016." Oslo/Kongsvinger: Statistics Norway.

de Vuijst, E., M. van Ham, and R. Kleinhans. 2017. "The moderating effect of higher education on the intergenerational transmission of residing in poverty neighbourhoods." Environment and Planning A: Economy and Space 49(9):2135-2154.

Drouhot, L.G.and V. Nee. 2019. "Assimilation and the Second Generation in Europe and America: Blending and Segregating Social Dynamics Between Immigrants and Natives." Annual Review of Sociology 45(1):177-199.

Duncan, B.and S.J. Trejo. 2015. "Assessing the Socioeconomic Mobility and Integration of U.S. Immigrants and Their Descendants." Annals of the American Academy of Political and Social Science 657(1):108-135.

Duncan, O.D.and S. Lieberson. 1959. "Ethnic segregation and assimilation." American Journal of Sociology 64(4):364-374.

Dustmann, C.and A. Glitz. 2011. "Migration and Education." Pp. 327-439 in Handbook of the Economics of Education, edited by S.M. Eric A. Hanushek and W. Ludger: Elsevier.

Ellen, I.G. 2000. Sharing America's neighborhoods. Cambridge: Harvard University Press.

Foner, N.and J. Dreby. 2011. "Relations Between the Generations in Immigrant Families." Annual Review of Sociology 37(1):545-564.

Galloway, T.A., B. Gustafsson, P.J. Pedersen, and T. Österberg. 2015. "Immigrant Child Poverty: The Achilles Heel of the Scandinavian Welfare State." Pp. 185-219 in Measurement of Poverty, Deprivation, and Economic Mobility, edited by T.I. Garner and K.S. Short: Emerald Group Publishing Limited.

Galster, G.and T. Wessel. 2019. "Reproduction of social inequality through housing: A threegenerational study from Norway." Social Science Research 78:119-136.

Godøy, A. 2017. "Local labor markets and earnings of refugee immigrants." Empirical Economics 52(1):31-58.

Gordon, M.M. 1964. Assimilation in American Life: The Role of Race, Religion, and National Origins. New York: Oxford University Press.

Gustafsson, B., K. Katz, and T. Österberg. 2017. "Residential Segregation from Generation to Generation: Intergenerational Association in Socio-Spatial Context Among Visible Minorities and the Majority Population in Metropolitan Sweden." Population, Space and Place 23(4).

Haller, W., A. Portes, and S.M. Lynch. 2011. "Dreams Fulfilled, Dreams Shattered: Determinants of Segmented Assimilation in the Second Generation." Social Forces 89(3):733-762.

Heath, A.F., C. Rothon, and E. Kilpi. 2008. "The Second Generation in Western Europe: Education, Unemployment, and Occupational Attainment." Annual Review of Sociology 34:211-235. 
Hermansen, A.S. 2016. "Moving Up or Falling Behind? Intergenerational Socioeconomic Transmission among Children of Immigrants in Norway." European Sociological Review 32(5):675-689.

—. 2017. "Et egalitært og velferdsstatlig integreringsparadoks?" Norsk sosiologisk tidsskrift $1(1): 15-34$.

Hermansen, A.S.and G.E. Birkelund. 2015. "The Impact of Immigrant Classmates on Educational Outcomes." Social Forces 94(2):615-646.

Hermansen, A.S., N.T. Borgen, and A. Mastekaasa. 2020. "Long-term trends in adult socioeconomic resemblance between former schoolmates and neighbouring children." European Sociological Review 36(3):366-380.

Hidalgo, M.C.and B. Hernandez. 2001. "Place attachment: Conceptual and empirical questions." Journal of environmental psychology 21(3):273-281.

Johnson, K., J. Pais, and S.J. South. 2012. "Minority population concentration and earnings: Evidence from fixed-effects models." Social Forces 91(1):181-208.

Koopmans, R. 2010. "Trade-Offs between Equality and Difference: Immigrant Integration, Multiculturalism and the Welfare State in Cross-National Perspective." Journal of Ethnic and Migration Studies 36(1):1-26.

Kornstad, T., T. Skjerpen, and L.S. Stambøl. 2018. "Utviklingen i bostedssegregering i utvalgte store og sentrale kommuner etter 2005." Oslo/Kongsvinger: Statistics Norway.

Logan, J.R.and R.D. Alba. 1993. "Locational returns to human capital: Minority access to suburban community resources." Demography 30(2):243-268.

Logan, J.R., W. Zhang, and R.D. Alba. 2002. "Immigrant enclaves and ethnic communities in New York and Los Angeles." American Sociological Review:299-322.

Løken, K.V., K.E. Lommerud, and S. Lundberg. 2013. "Your Place or Mine? On the Residence Choice of Young Couples in Norway." Demography 50(1):285-310.

Massey, D.S. 1985. "Ethnic residential segregation: A theoretical synthesis and empirical review." Sociology and social research 69(3):315-350.

Massey, D.S.and N.A. Denton. 1985. "Spatial assimilation as a socioeconomic outcome." American Sociological Review:94-106.

McAvay, H. 2018. "How Durable Are Ethnoracial Segregation and Spatial Disadvantage? Intergenerational Contextual Mobility in France." Demography 55(4):1507-1545.

Musterd, S. 2005. "Social and Ethnic Segregation in Europe: Levels, Causes, and Effects." Journal of Urban Affairs 27(3):331-348.

Nordvik, V.and L. Hedman. 2019. "Neighbourhood attainment of children of immigrants in Greater Oslo: Intergenerational inertia and the role of education." Population, Space and Place:e2192. 
OECD. 2017. International Migration Outlook. Paris: OECD.

Pais, J. 2017. "Intergenerational neighborhood attainment and the legacy of racial residential segregation: A causal mediation analysis." Demography 54(4):1221-1250.

Park, R.E. 1926. "The urban community as a spatial pattern and a moral order." Pp. 3-18 in The Urban Community, edited by E.W. Burgess. Chicago: University of Chicago Press.

Park, R.E.and E.W. Burgess. 1921. Introduction to the Science of Sociology. Chicago: University of Chicago Press.

Portes, A.and R.G. Rumbaut. 2001. Legacies: The Story of the Immigrant Second Generation. Berkeley: Russell Sage Foundation.

Price, C. 1969. "The study of assimilation." Pp. 181-237 in Migration, edited by J.A. Jackson. London: Cambridge University Press.

Quillian, L., A. Heath, D. Pager, A.H. Midtbøen, F. Fleischmann, and O. Hexel. 2019. "Do Some Countries Discriminate More than Others? Evidence from 97 Field Experiments of Racial Discrimination in Hiring." Sociological Science 6:467-496.

Reisel, L., A.S. Hermansen, and M.T. Kindt. 2019. "Norway: ethnic (in)equality in a socialdemocratic welfare state." Pp. 843-884 in The Palgrave Handbook of Race and Ethnic Inequalities in Education, edited by P.A.J. Stevens and A.G. Dworkin. London: Palgrave Macmillan.

Sharkey, P. 2008. "The intergenerational transmission of context." American Journal of Sociology 113(4):931-969.

Sharkey, P.and J.W. Faber. 2014. "Where, When, Why, and For Whom Do Residential Contexts Matter? Moving Away from the Dichotomous Understanding of Neighborhood Effects." Annual Review of Sociology 40(1):559-579.

South, S.J., Y. Huang, A. Spring, and K. Crowder. 2016. "Neighborhood Attainment over the Adult Life Course." American Sociological Review 81(6):1276-1304.

Statistics Norway. 1999. "Regional Classifications. A Survey of Standards in Official Statistics of Norway." Oslo/Kongsvinger: Statistics Norway.

- 2020. Immigrants and Norwegian-Born to Immigrant Parents, January 1, 2019 [available at <http://ssb.no/en/befolkning/statistikker/innvbef>> ]. Oslo/Kongsvinger: Statistics Norway.

Swift, A. 2004. "Would Perfect Mobility be Perfect?" European Sociological Review 20(1):111.

Swisher, R.R., D.C. Kuhl, and J.M. Chavez. 2013. "Racial and ethnic differences in neighborhood attainments in the transition to adulthood." Social Forces 91(4):1399-1428.

Tran, V.C. 2020. "Second-Generation Contextual Mobility: Neighborhood Attainment from Birth to Young Adulthood in the United States." International Migration Review 54(2):356387. 
Van Ham, M., L. Hedman, D. Manley, R. Coulter, and J. Östh. 2014. "Intergenerational transmission of neighbourhood poverty: an analysis of neighbourhood histories of individuals." Transactions of the Institute of British Geographers 39(3):402-417.

Vartanian, T.P., P.W. Buck, and P. Gleason. 2007. "Intergenerational neighborhood-type mobility: examining differences between blacks and whites." Housing Studies 22(5):833-856.

Wessel, T., R. Andersson, T. Kauppinen, and H.S. Andersen. 2017. "Spatial Integration of Immigrants in Nordic Cities: The Relevance of Spatial Assimilation Theory in a Welfare State Context." Urban Affairs Review 53(5):812-842.

Wessel, T.and V. Nordvik. 2019. "Mixed neighbourhoods and native out-mobility in the Oslo region: The importance of parenthood." Urban Studies 56(5):885-905.

White, M.J.and J.E. Glick. 2009. Achieving Anew: How New Immigrants Do in American Schools, Jobs, and Neighborhoods. New York: Russell Sage Foundation.

Xie, Y.and M. Gough. 2011. "Ethnic Enclaves and the Earnings of Immigrants." Demography 48(4):1293-1315.

Zorlu, A. 2009. "Ethnic differences in spatial mobility: the impact of family ties." Population, Space and Place 15(4):323-342.

Zuccotti, C.V. 2019. "Ethnicity and neighbourhood attainment in England and Wales: A study of second generations' spatial integration." Population, Space and Place:e2252.

Åslund, O., P.-A. Edin, P. Fredriksson, and H. Grönqvist. 2011. "Peers, Neighborhoods, and Immigrant Student Achievement: Evidence from a Placement Policy." American Economic Journal: Applied Economics 3(2):67-95. 
Table 1. Descriptive statistics by immigrant background.

\begin{tabular}{|c|c|c|c|c|c|c|}
\hline \multirow[b]{2}{*}{ Variable } & \multicolumn{2}{|c|}{ Children of immigrants } & \multicolumn{2}{|c|}{ Children of natives } & \multirow[b]{2}{*}{ Difference } & \multirow[b]{2}{*}{ Range } \\
\hline & Mean & SD & Mean & SD & & \\
\hline \multicolumn{7}{|l|}{ Adult neighborhood context } \\
\hline \multicolumn{7}{|l|}{ Mean of annual earnings } \\
\hline Unstandardized (2018 NOK) & 484,022 & 77,038 & 458,074 & 77,676 & $25,949 * * *$ & $47,985-1,230,411$ \\
\hline Standardized rank (percentiles) & 0.390 & 0.296 & 0.506 & 0.287 & $0.117 * * *$ & $0.0-100.0$ \\
\hline \multicolumn{7}{|l|}{ Share of native-origin residents } \\
\hline Unstandardized (fraction) & 0.651 & 0.173 & 0.812 & 0.105 & $0.162 * * *$ & $0.066-1.000$ \\
\hline Standardized rank (percentiles) & 0.238 & 0.249 & 0.514 & 0.284 & $0.277 * * *$ & $0.0-100.0$ \\
\hline \multicolumn{7}{|l|}{ Childhood neighborhood context } \\
\hline \multicolumn{7}{|l|}{ Mean of annual earnings } \\
\hline Unstandardized (2018 NOK) & 310,991 & 53,389 & 321,355 & 63,631 & $10,364 * * *$ & $87,731-951,688$ \\
\hline Standardized rank (percentiles) & 0.384 & 0.263 & 0.506 & 0.289 & $0.122 * * *$ & $0.0-100.0$ \\
\hline \multicolumn{7}{|l|}{ Share of native-origin residents } \\
\hline Unstandardized (fraction) & 0.780 & 0.155 & 0.924 & 0.065 & $0.147 * * *$ & $0.115-1.000$ \\
\hline Standardized rank (percentiles) & 0.173 & 0.201 & 0.518 & 0.282 & $0.345 * * *$ & $0.0-100.0$ \\
\hline \multicolumn{7}{|l|}{ Individual and parental variables } \\
\hline Earnings rank & 0.447 & 0.301 & 0.503 & 0.288 & $0.056 * * *$ & $0.0-100.0$ \\
\hline \multicolumn{7}{|l|}{ Educational attainment } \\
\hline Less than upper secondary & 0.290 & & 0.183 & & $-0.106^{* * *}$ & $0-1$ \\
\hline Full upper secondary & 0.282 & & 0.318 & & $0.317 * * *$ & $0-1$ \\
\hline University degree, short & 0.267 & & 0.329 & & $0.062 * * *$ & $0-1$ \\
\hline University degree, long & 0.161 & & 0.169 & & $0.008 *$ & $0-1$ \\
\hline Parents' earnings rank & 0.222 & 0.228 & 0.515 & 0.284 & $0.294 * * *$ & $0.0-100.0$ \\
\hline \multicolumn{7}{|l|}{ Parents' highest education } \\
\hline Less than upper secondary & 0.432 & & 0.293 & & $-0.138 * * *$ & $0-1$ \\
\hline Full upper secondary & 0.183 & & 0.260 & & $0.077 * * *$ & $0-1$ \\
\hline University degree, short & 0.195 & & 0.286 & & $0.091 * * *$ & $0-1$ \\
\hline University degree, long & 0.077 & & 0.149 & & $0.072 * * *$ & $0-1$ \\
\hline No education registered & 0.113 & & 0.011 & & $-0.102 * * *$ & $0-1$ \\
\hline Gender $($ male $=0$, female $=1)$ & 0.480 & & 0.489 & & $0.009 *$ & $0-1$ \\
\hline Intact or reconstituted family & 0.809 & & 0.755 & & $-0.054 * * *$ & $0-1$ \\
\hline Mother's age at birth & 27.1 & 5.5 & 27.3 & 4.9 & $0.256^{* * *} *$ & $15-45$ \\
\hline First-born child of mother & 0.367 & & 0.460 & & $0.093 * * *$ & $0-1$ \\
\hline Number of siblings & 2.69 & 1.71 & 1.52 & 1.00 & $-1.168 * * *$ & $0-16$ \\
\hline Birth cohorts & 1982.8 & 4.0 & 1981.1 & 4.4 & $-1.8^{* * *}$ & $1974-1988$ \\
\hline Observations & 8,547 & & 156,776 & & & \\
\hline
\end{tabular}

Note: Standard deviations are not presented for discrete variables, as the full distribution of responses is shown.

Source: Authors' caulculations based on administrative data from Statistics Norway.

$* \mathrm{p}<0.05, * * \mathrm{p}<0.01, * * * \mathrm{p}<0.001$ 
Table 2. Estimated as sociations between economic and ethnic neighborhood rank in childhood and adulthood from OLS regressions.

Panel A. Economic neighborhood rank in adulthood

\begin{tabular}{|c|c|c|c|c|c|c|c|c|c|c|}
\hline & \multicolumn{5}{|l|}{ Natives } & \multicolumn{5}{|c|}{ Immigrants } \\
\hline & (1) & (2) & (3) & (4) & (5) & (1) & (2) & (3) & (4) & (5) \\
\hline Childhood economic neighborhood rank & $\begin{array}{l}0.439 * * * \\
(0.002)\end{array}$ & $\begin{array}{l}0.293 * * * \\
(0.002)\end{array}$ & $\begin{array}{l}0.240 * * * \\
(0.002)\end{array}$ & $\begin{array}{l}0.231 * * * \\
(0.002)\end{array}$ & $\begin{array}{l}0.215^{* * *} * \\
(0.002)\end{array}$ & $\begin{array}{l}0.367 * * * \\
(0.008)\end{array}$ & $\begin{array}{l}0.297 * * * \\
(0.009)\end{array}$ & $\begin{array}{l}0.266 * * * \\
(0.009)\end{array}$ & $\begin{array}{l}0.253 * * * \\
(0.010)\end{array}$ & $\begin{array}{l}0.240 * * * \\
(0.010)\end{array}$ \\
\hline Reduction $(\%)$ & - & $33.3 \%$ & $45.3 \%$ & $47.4 \%$ & $51.0 \%$ & - & $19.1 \%$ & $27.5 \%$ & $31.1 \%$ & $34.6 \%$ \\
\hline Childhood municipality fixed effects & No & Yes & Yes & Yes & Yes & No & Yes & Yes & Yes & Yes \\
\hline Individual socioeconomic controls & No & No & Yes & No & Yes & No & No & Yes & No & Yes \\
\hline Family background controls & No & No & No & Yes & Yes & No & No & No & Yes & Yes \\
\hline$R^{2}$ & 0.195 & 0.233 & 0.271 & 0.25 & 0.275 & 0.109 & 0.156 & 0.193 & 0.177 & 0.204 \\
\hline Number of observations & 297,214 & 297,214 & 297,214 & 297,214 & 297,214 & 16,338 & 16,338 & 16,338 & 16,338 & 16,338 \\
\hline \multicolumn{11}{|c|}{ Panel B. Ethnic neighborhood rank in adulthood } \\
\hline & \multicolumn{5}{|l|}{ Natives } & \multicolumn{5}{|c|}{ Immigrants } \\
\hline & $(1)$ & (2) & $(3)$ & (4) & $(5)$ & $(1)$ & $(2)$ & (3) & (4) & $(5)$ \\
\hline Childhood ethnic neighborhood rank & $\begin{array}{l}0.287 * * * \\
(0.002)\end{array}$ & $\begin{array}{l}0.125 * * * \\
(0.002)\end{array}$ & $\begin{array}{l}0.128 * * * \\
(0.002)\end{array}$ & $\begin{array}{l}0.129 * * * \\
(0.002)\end{array}$ & $\begin{array}{l}0.128 * * * \\
(0.002)\end{array}$ & $\begin{array}{l}0.480 * * * \\
(0.009)\end{array}$ & $\begin{array}{l}0.236 * * * \\
(0.011)\end{array}$ & $\begin{array}{l}0.226 * * * \\
(0.011)\end{array}$ & $\begin{array}{l}0.199 * * * \\
(0.011)\end{array}$ & $\begin{array}{l}0.196 * * * \\
(0.011)\end{array}$ \\
\hline Reduction $(\%)$ & - & $56.4 \%$ & $55.4 \%$ & $55.1 \%$ & $55.4 \%$ & - & $50.8 \%$ & $52.9 \%$ & $58.5 \%$ & $59.2 \%$ \\
\hline Childhood municipality fixed effects & No & Yes & Yes & Yes & Yes & No & Yes & Yes & Yes & Yes \\
\hline Individual socioeconomic controls & No & No & Yes & No & Yes & No & No & Yes & No & Yes \\
\hline Family background controls & No & No & No & Yes & Yes & No & No & No & Yes & Yes \\
\hline$R^{2}$ & 0.084 & 0.152 & 0.165 & 0.161 & 0.168 & 0.154 & 0.237 & 0.242 & 0.248 & 0.251 \\
\hline Number of observations & 297,471 & 297,471 & 297,471 & 297,471 & 297,471 & 16,345 & 16,345 & 16,345 & 16,345 & 16,345 \\
\hline
\end{tabular}

Note: All models control for gender and birth cohort. Individual socioeconomic controls include educational attaiment and adult earnings quintile. Family background controls include parental highest education, parental earnings quintile, mother's age at birth, first-born child of mother, number of siblings, and intact/reconstituted family. Standard errors are shown in parentheses. Huber-White standard errors robust to clustering and heteroskedasticity within neighborhood units are shown in parentheses.

$* \mathrm{p}<0.05, * * \mathrm{p}<0.01, * * * \mathrm{p}<0.001$ 
(a) Economic neighborhood rank in childhood

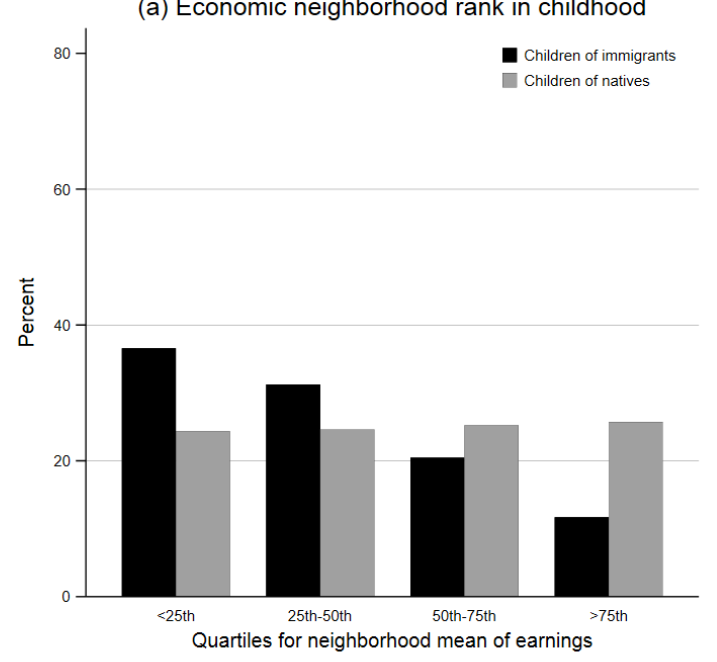

(c) Ethnic neighborhood rank in childhood

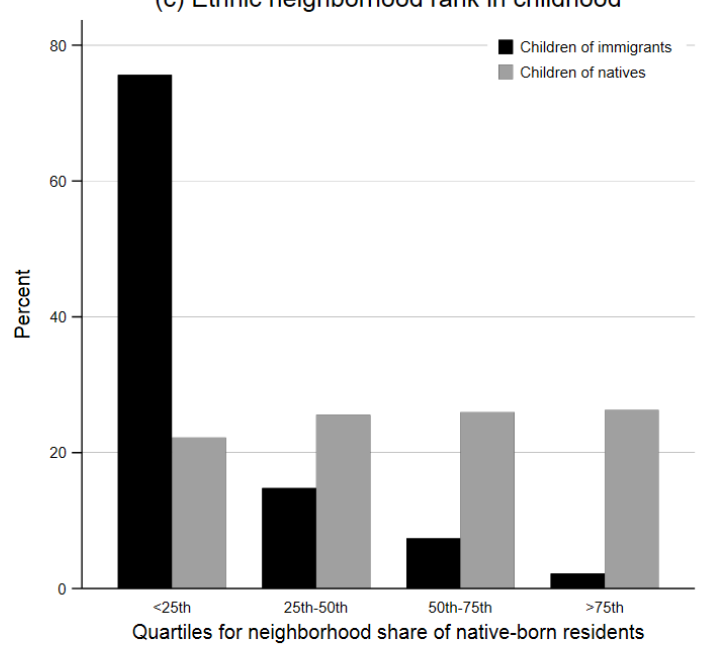

(b) Economic neighborhood rank in adulthood

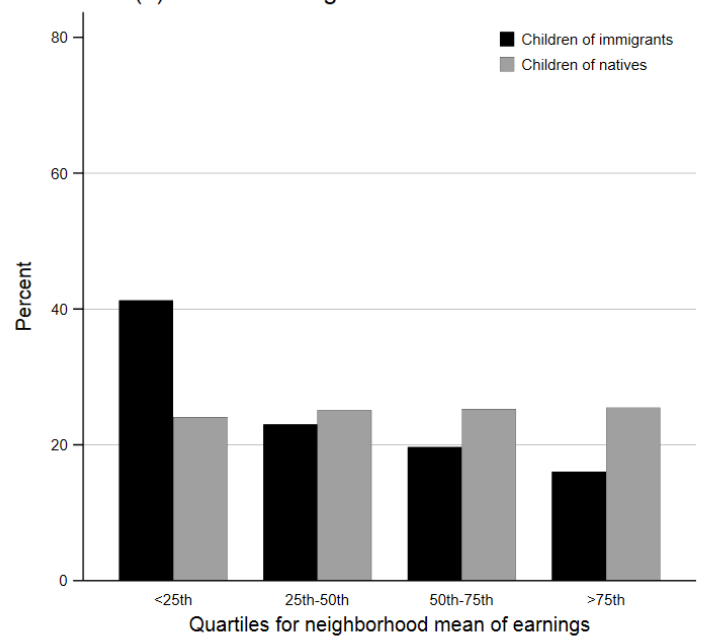

(d) Ethnic neighborhood rank in adulthood

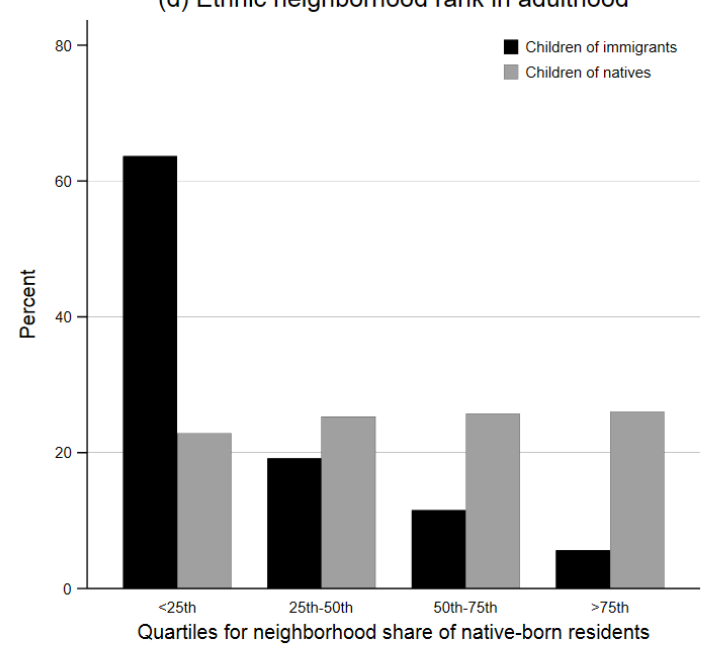

Figure 1. Distribution of neighborhood quartiles in mean of annual earnings and share of native-born residents in childhood and adulthood for immigrant descendants and natives. 
(a) Economic neighborhood rank

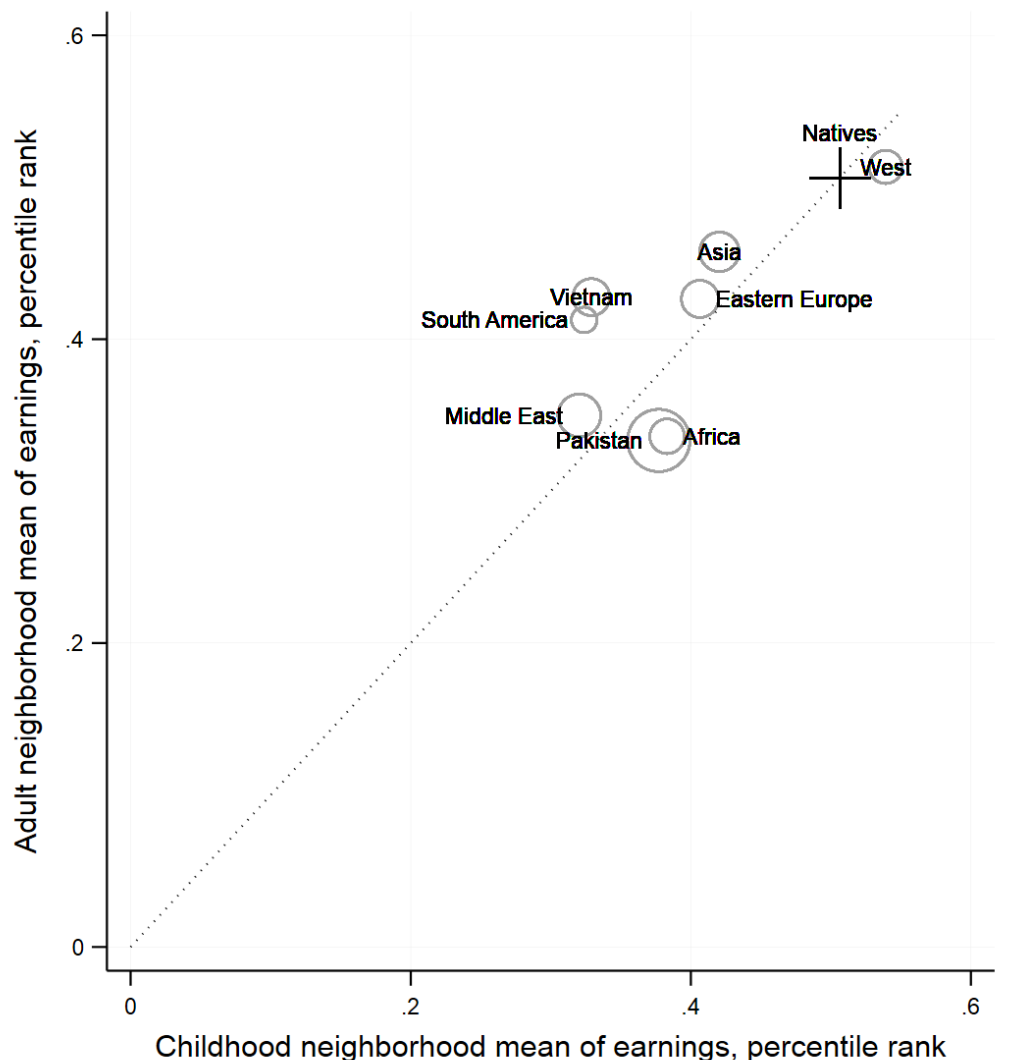

(b) Ethnic neighborhood rank

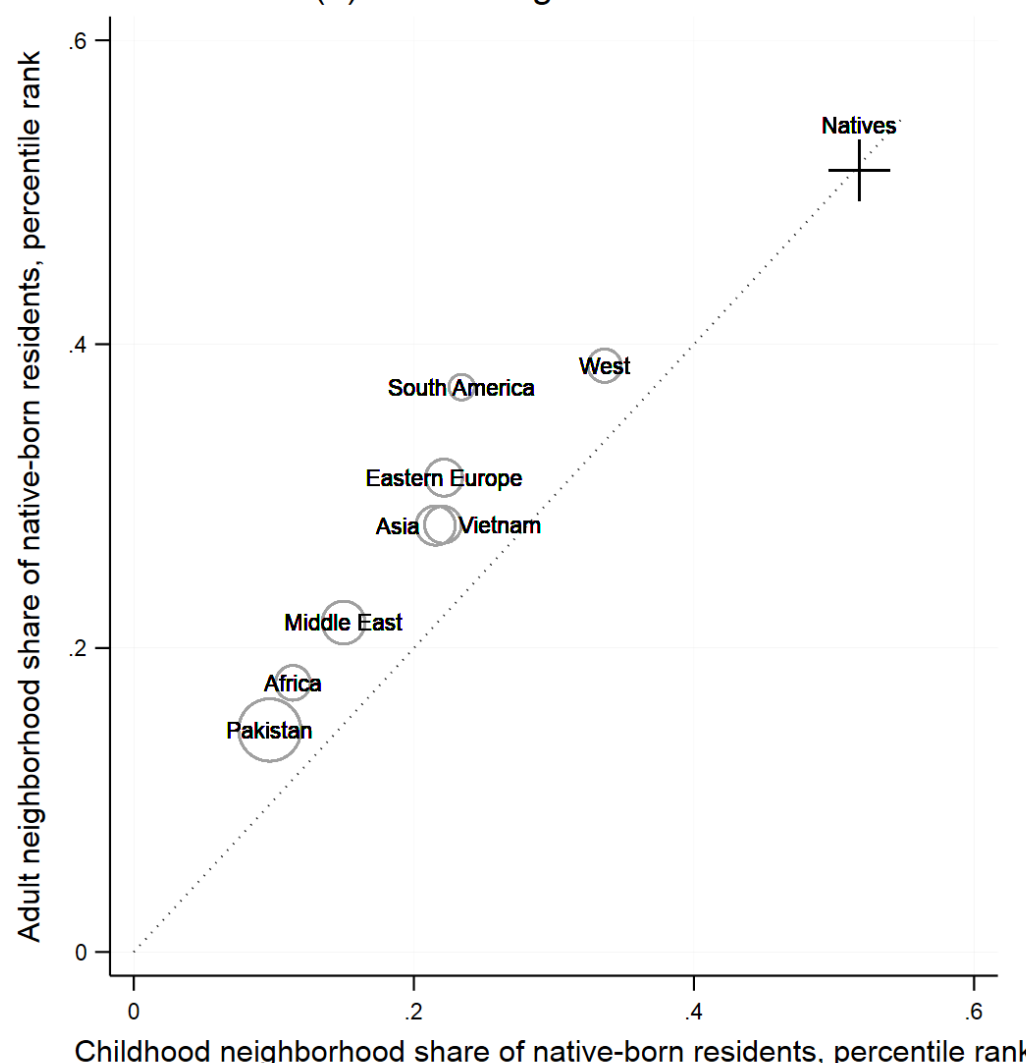

Figure 2. Relation between economic and ethnic neighborhood ranks in childhood and adulthood for immigrant descendants from different regions of origin.

Note: The figure presents nonparametric scatter plots of the mean neighborhood rank in childhood and adulthood by origin region among the immigrant descendants. Each panel plots the mean childhood and adulthood neighborhood position within each region of origin group among the immigrant descendants. The center of the overlaid scatter point circles refers to the conditional childhood-adulthood neighborhood mean for each region of origin group. The size of each circle is proportional to the number of individuals in each region of origin group. The center of the black cross represents the conditional childhood-adulthood neighborhood mean for children of natives. For reference purposes, the solid grey line refers to the diagonal where the percentile rank in the neighborhood distribution in childhood and adulthood is equal. 
(a) Economic neighborhood rank

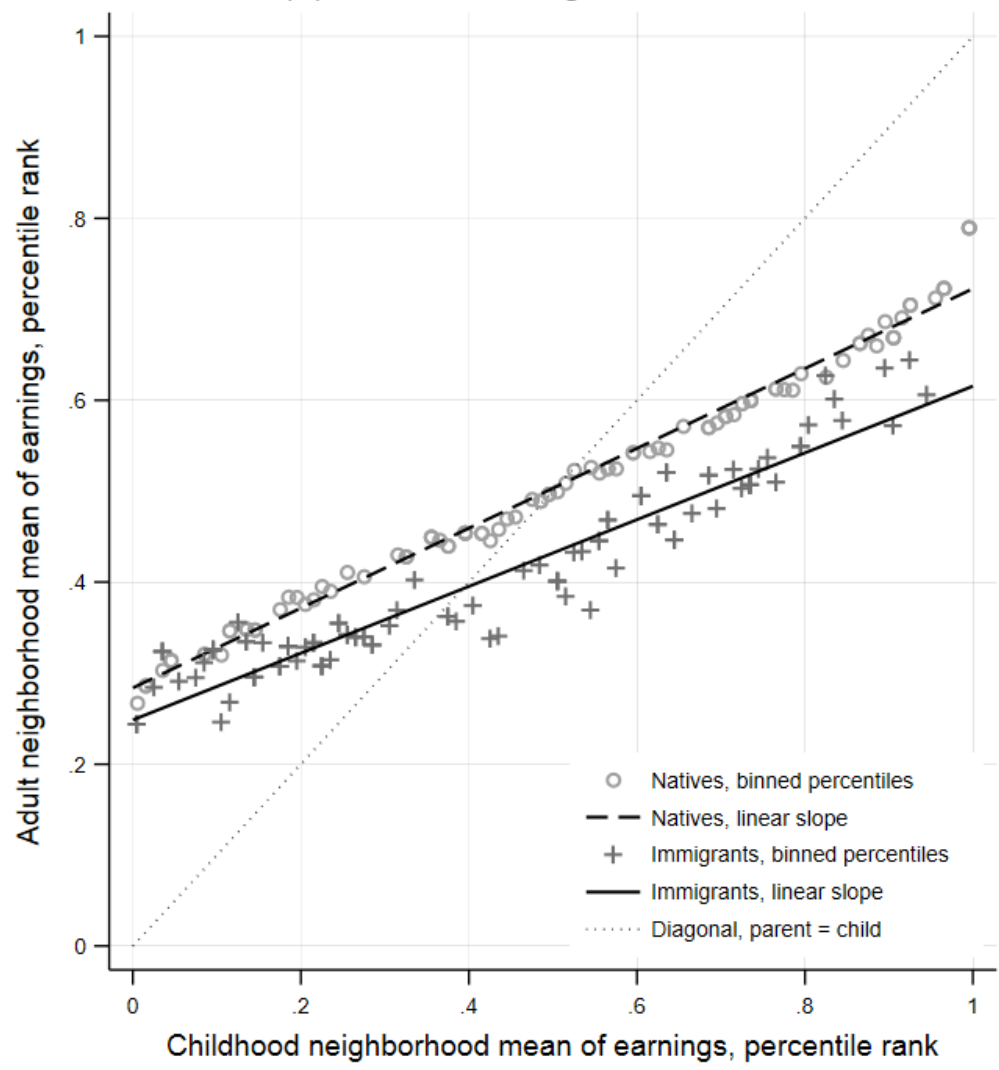

(b) Ethnic neighborhood rank

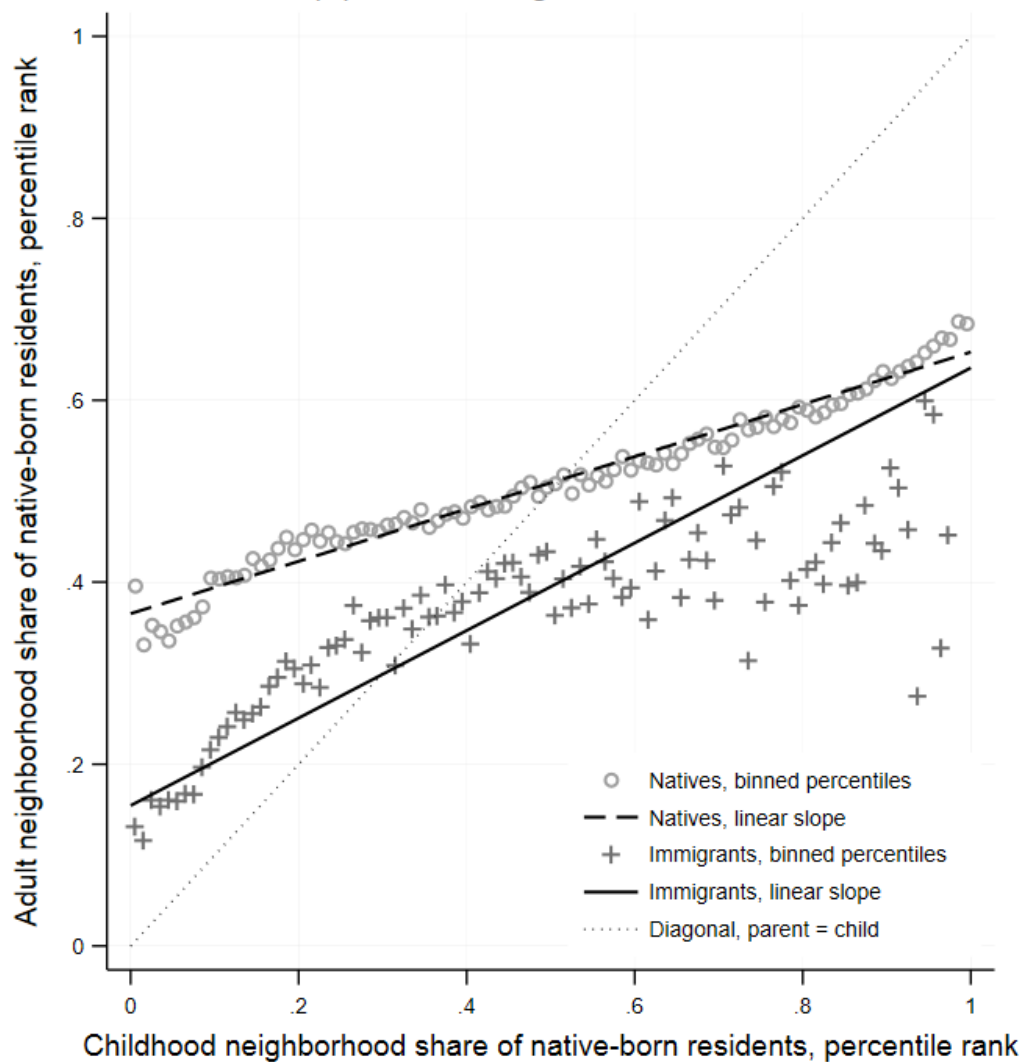

Figure 3. Economic and ethnic neighborhood ranks in adulthood by childhood neighborhood rank separately for natives and immigrant descendants.

Note: The graphs present the nonparametric relationship between neighborhood percentile rank in childhood and adulthood for natives and immigrant descendants. Each panel plots the mean neighborhood rank in adulthood within each childhood neighborhood percentile rank bin separately for immigrant descendants and native Norwegians. The grey lines refer to the bivariate slope between neighborhood mean of earnings in childhood and adulthood estimated on the individual-level data separately by immigrant background. For reference purposes, the solid grey line refers to the diagonal where the percentile rank in the neighborhood distribution in childhood and adulthood is equal. 
(a) Economic neighborhood rank
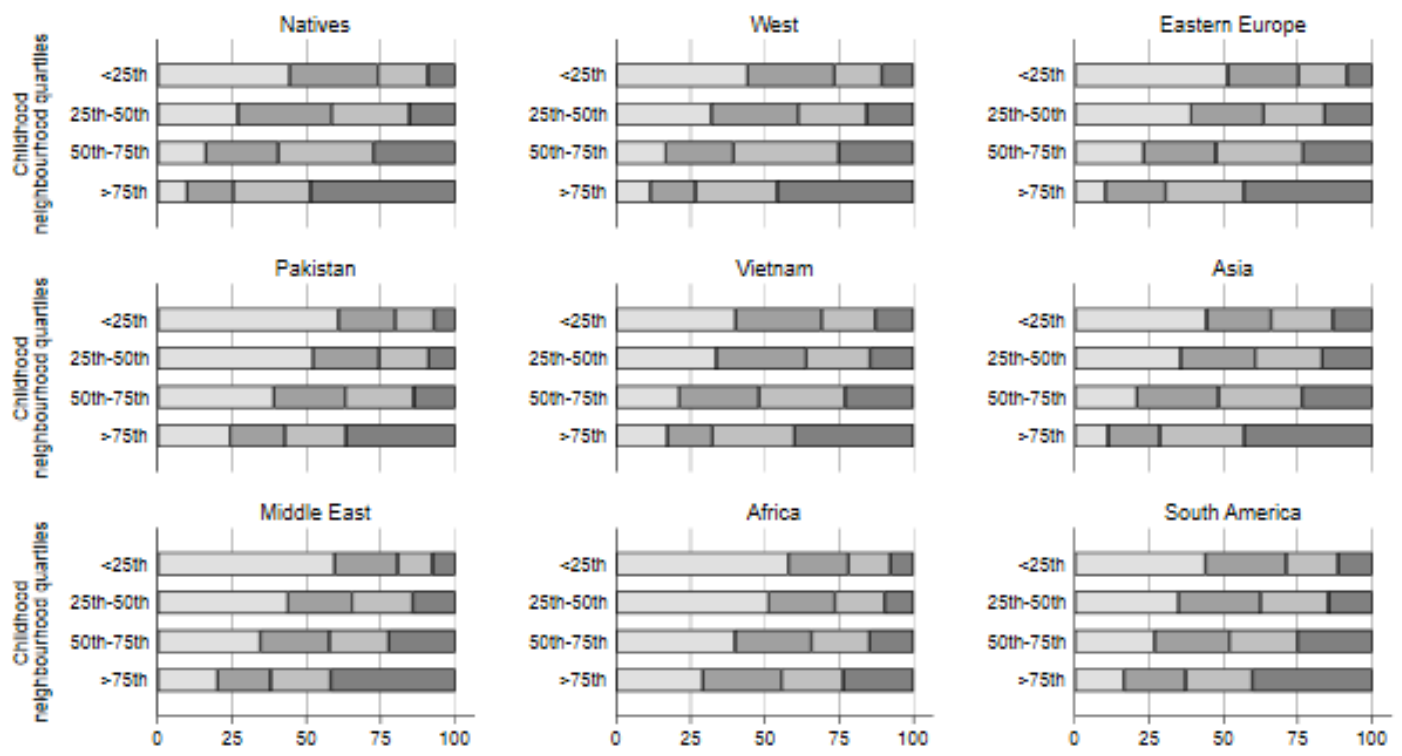

Quartiles of adult neigborhood mean of earnings, percent

a $<25$ th

a 25 th -50 th

a 50 th -75 th

a $>57$ th

(b) Ethnic neighborhood rank
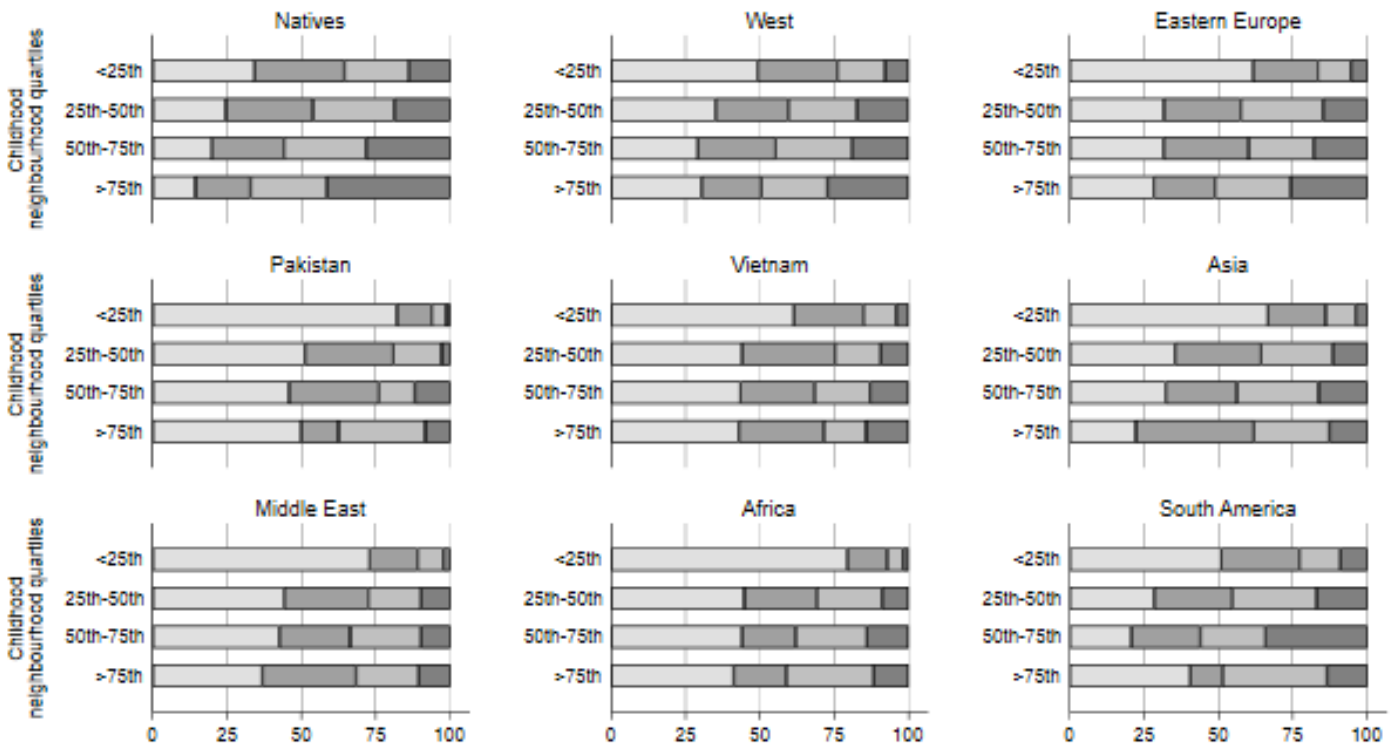

Quartiles of adult neigborhood share of native-born residents, percent
a $<25$ th
a 25 th-50th
a 50 th -75 th
a $>75$ th

Figure 4. Outflow rates from childhood neighborhood quartiles in terms of economic and ethnic neighborhood rank from mobility tables for natives and immigrant descendants from different regions of origin. 
(a) Economic neighborhood rank

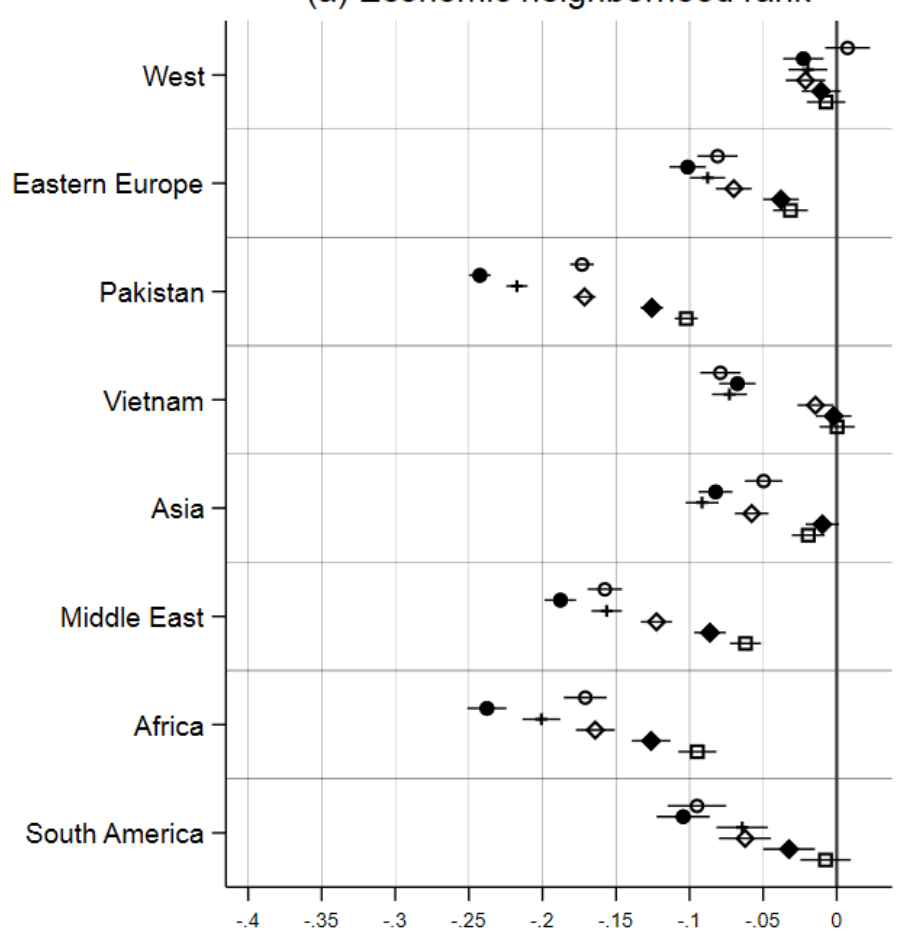

Native-immigrant adult neighbourhood gap, percentile rank (Prediction with 95\% confidence interval)

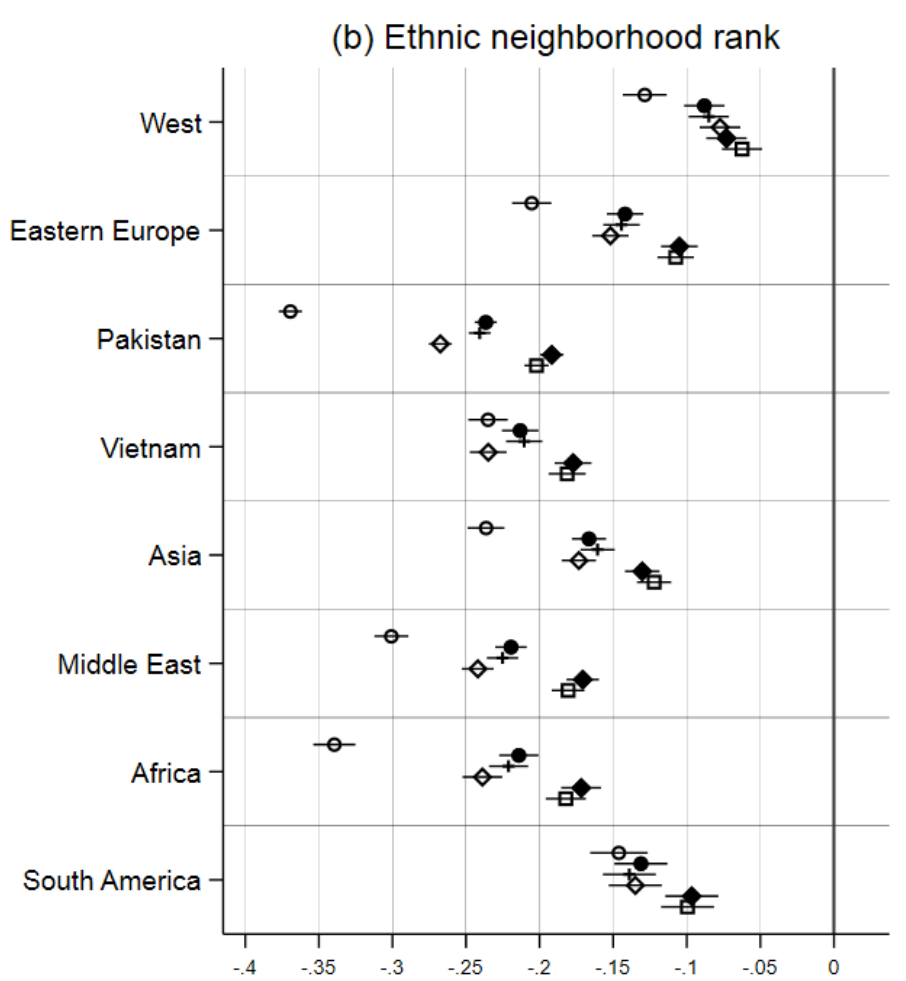

Native-immigrant adult neighbourhood gap percentile rank

(Prediction with $95 \%$ confidence interval)
O Model 1:
Model 2:
Model 3:
Model 4:
+ Baseline, muni FE
$\checkmark$ Baseline, muni FE
Model 5:
Model 6:
Baseline, neighborhood FE
and municipality FE and adult attainments and family background
Baseline, neighborhood $\mathrm{F}$
and all observed characteristics

Figure 5. Estimated native-immigrant gaps in economic and ethnic neighborhood rank in adulthood for different regions of origin from OLS regressions.

Note: The black vertical line refers to the native Norwegian reference group and the different markers to the estimated gaps from different model specifications for each immigrant origin group. Model 1 controls for gender and birth cohort dummies. Model 2 controls for childhood municipality fixed effects, gender, and birth cohort dummies. Model 3 controls for childhood municipality fixed effects, individual educational attainment and adult earnings quintile, gender, and birth cohort dummies. Model 4 controls for childhood municipality fixed effects parental highest education, parental earnings quintile, mother's age at birth, whether the child was the first-born of his or her mother, number of siblings, gender, and birth cohort dummies. Model 5 controls for childhood neighborhood fixed effects, economic and ethnic neighborhood rank (linear and squared terms), gender, and birth cohort dummies. Model 6 controls for childhod neighborhood fixed effects and all other observed characteristics of individuals, their family background, and childhood neighborhood characteristics. The 95\% confidence intervals are obtained from Huber-White standard errors robust to clustering and heteroskedasticity within neighborhood units. 


\section{APPENDIX TABLES AND FIGURES}

Table A1. Regional origin groups among the immigrant descendants

\begin{tabular}{|c|c|c|c|c|c|}
\hline Regions of origin & $\operatorname{Men}(\mathrm{N})$ & Women $(\mathrm{N})$ & All $(\mathrm{N})$ & All $(\%)$ & Largest countries of origin $(n \geq 15)$ \\
\hline West & 728 & 652 & 1,380 & 8.4 & $\begin{array}{l}\text { Denmark }(n=314) \text {, Sweden }(n=231) \text {, United Kingdom }(n=158) \text {, Iceland } \\
(n=126) \text {, Germany }(n=99) \text {, Finland }(n=81) \text {, the Netherlands }(n=74) \text {, USA } \\
(n=66) \text { Spain }(n=33) \text {, France }(n=27) \text {, Switzerland }(n=25) \text {, Italy }(n=22) \text {, } \\
\text { Portugal }(n=22) \text {, Austria }(n=19) \text {, Belgium }(n=15)\end{array}$ \\
\hline Eastern Europe & 852 & 861 & 1,713 & 10.5 & $\begin{array}{l}\text { Poland }(n=442) \text {, Kosovo }(n=329) \text {, Macedonia }(n=284) \text {, Bosnia- } \\
\text { Herzegovina }(n=213) \text {, Croatia }(n=147) \text {, Serbia }(n=121) \text {, Hungary }(n=58) \text {, } \\
\text { Chech Republic }(n=36) \text {, Russia }(n=26) \text {, Romania }(n=21)\end{array}$ \\
\hline Pakistan & 2,632 & 2,355 & 4,987 & 30.5 & Pakistan \\
\hline Vietnam & 892 & 816 & 1,708 & 10.5 & Vietnam \\
\hline Asia & 1,002 & 950 & 1,952 & 11.9 & $\begin{array}{l}\text { India }(n=769) \text {, Phillippines }(n=361) \text {, Sri Lanka }(n=328) \text {, China }(n=119) \text {, } \\
\text { Hongkong }(n=93) \text {, Thailand }(n=83) \text {, Bangladesh }(n=48) \text {, Cambodia }(n=31) \text {, } \\
\text { South-Korea }(n=21) \text {, Singapore }(n=20) \text {, Indonesia }(n=17) \text {, Malaysia }(n=16)\end{array}$ \\
\hline Middle East & 1,201 & 1,108 & 2,309 & 14.1 & $\begin{array}{l}\text { Turkey }(n=1,3141) \text {, Iran }(n=598) \text {, Iraq }(n=184) \text {, Lebanon }(n=90) \text {, Syria } \\
(n=49) \text {, Afghanistan }(n=27)\end{array}$ \\
\hline Africa & 786 & 708 & 1,494 & 9.1 & $\begin{array}{l}\text { Morocco }(n=721) \text {, Somalia }(n=208) \text {, Eritrea }(n=104) \text {, Cape Verde }(n=57) \text {, } \\
\text { Ghana }(n=47) \text {, Ethiopia }(n=46) \text {, Kenya }(n=45) \text {, Gambia }(n=42) \text {, Algeria } \\
(n=37) \text {, Nigeria }(n=35) \text {, Tunisia }(n=28) \text {, Mauritius }(n=27) \text {, Uganda }(n=26)\end{array}$ \\
\hline South America & 404 & 398 & 802 & 4.9 & Chile $(n=624)$, Colombia $(n=25)$, Peru $(n=24)$, Brasil $(n=22)$, Uruguay $(n=15)$ \\
\hline Total & 8,497 & 7,848 & 16,345 & 100.0 & \\
\hline
\end{tabular}

Note: The table shows the number of total number of observations ans separately by gender for each region of origin. For each ethnic minority group, all countries of origin with 15 or more observations are listed. 
Table A2. Neighborhood mean rank and quartiles in childhood and adulthood for natives and immigrant

\begin{tabular}{|c|c|c|c|c|c|c|c|c|c|c|}
\hline & \multicolumn{5}{|c|}{ Panel A. Economic composition } & \multicolumn{5}{|c|}{ Panel B. Ethnic composition } \\
\hline & \multirow[b]{2}{*}{$\begin{array}{c}\text { Rank } \\
\text { (mean) }\end{array}$} & \multicolumn{4}{|c|}{ Neighborhood quartiles (\%) } & \multirow[b]{2}{*}{$\begin{array}{c}\text { Rank } \\
\text { (mean) }\end{array}$} & \multicolumn{4}{|c|}{ Neighborhood quintiles (\%) } \\
\hline & & $<25$ th & 25-50th & $50-75$ th & $>75$ th & & $<25$ th & 25-50th & $50-75$ th & $>75$ th \\
\hline \multicolumn{11}{|l|}{ Natives } \\
\hline Childhood & 0.506 & 24.4 & 24.7 & 25.3 & 25.7 & 0.518 & 22.2 & 25.6 & 26.0 & 26.3 \\
\hline Adulthood & 0.506 & 24.1 & 25.1 & 25.3 & 25.5 & 0.514 & 22.9 & 25.3 & 25.7 & 26.1 \\
\hline \multicolumn{11}{|l|}{ West } \\
\hline Childhood & 0.539 & 22.3 & 21.6 & 24.8 & 31.3 & 0.336 & 45.2 & 28.5 & 19.1 & 7.2 \\
\hline Adulthood & 0.513 & 24.4 & 23.3 & 25.9 & 26.4 & 0.386 & 40.0 & 25.5 & 20.4 & 14.1 \\
\hline \multicolumn{11}{|c|}{ Eastern Europe } \\
\hline Childhood & 0.407 & 34.9 & 28.5 & 22.9 & 13.8 & 0.222 & 65.4 & 22.0 & 10.4 & 2.3 \\
\hline Adulthood & 0.427 & 35.8 & 23.6 & 21.8 & 18.8 & 0.312 & 51.1 & 23.4 & 16.2 & 9.3 \\
\hline \multicolumn{11}{|l|}{ Pakistan } \\
\hline Childhood & 0.377 & 34.4 & 36.1 & 20.4 & 9.1 & 0.097 & 89.5 & 7.8 & 2.2 & 0.5 \\
\hline Adulthood & 0.333 & 50.0 & 21.1 & 17.1 & 11.8 & 0.146 & 78.7 & 13.5 & 6.1 & 1.6 \\
\hline \multicolumn{11}{|l|}{ Vietnam } \\
\hline Childhood & 0.329 & 44.6 & 31.5 & 15.5 & 8.5 & 0.221 & 66.2 & 22.0 & 9.4 & 2.5 \\
\hline Adulthood & 0.428 & 33.3 & 27.8 & 21.6 & 17.4 & 0.281 & 55.4 & 25.4 & 12.8 & 6.4 \\
\hline \multicolumn{11}{|l|}{ Asia } \\
\hline Childhood & 0.420 & 31.9 & 29.8 & 24.5 & 13.8 & 0.216 & 68.4 & 17.7 & 10.7 & 3.2 \\
\hline Adulthood & 0.458 & 31.4 & 23.5 & 24.1 & 21.0 & 0.281 & 56.0 & 22.3 & 14.9 & 6.9 \\
\hline \multicolumn{11}{|l|}{ Middle East } \\
\hline Childhood & 0.320 & 45.2 & 30.5 & 18.7 & 5.6 & 0.150 & 80.5 & 11.2 & 6.7 & 1.7 \\
\hline Adulthood & 0.350 & 47.8 & 21.5 & 16.4 & 14.3 & 0.217 & 67.1 & 18.2 & 10.9 & 3.8 \\
\hline \multicolumn{11}{|l|}{ Africa } \\
\hline Childhood & 0.383 & 37.0 & 31.3 & 19.5 & 12.2 & 0.114 & 87.3 & 8.2 & 3.4 & 1.1 \\
\hline Adulthood & 0.336 & 48.8 & 22.7 & 16.8 & 11.7 & 0.177 & 74.9 & 14.5 & 7.6 & 3.0 \\
\hline \multicolumn{11}{|c|}{ South America } \\
\hline Childhood & 0.324 & 46.9 & 28.9 & 15.8 & 8.4 & 0.234 & 65.3 & 19.8 & 10.2 & 4.6 \\
\hline Adulthood & 0.413 & 36.3 & 26.4 & 20.3 & 17.0 & 0.372 & 42.9 & 25.2 & 18.6 & 13.3 \\
\hline
\end{tabular}

Note: Mean and quartiles for economic and ethnic neighborhood ranks in childhood and adulthood for each regional origin group among the immigrant descendants. 
(a) Economic neighborhood quartiles in childhood

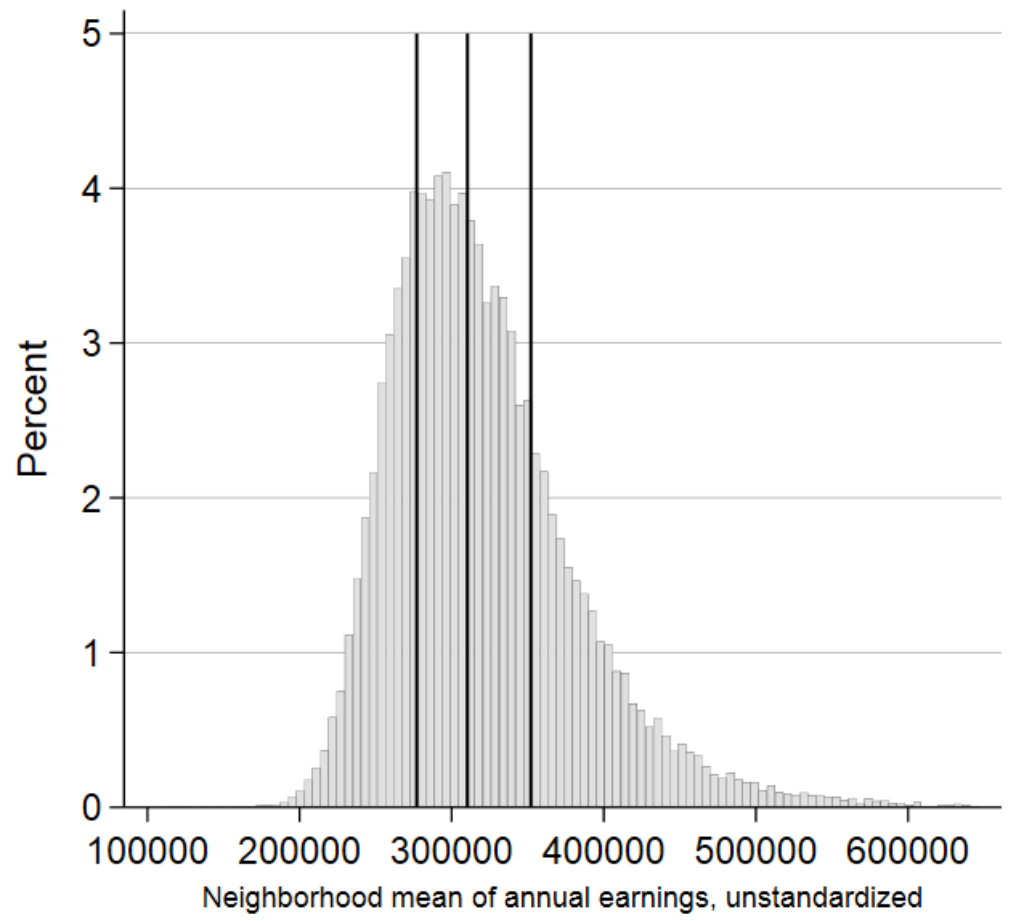

(b) Economic neighborhood quartiles in adulthood

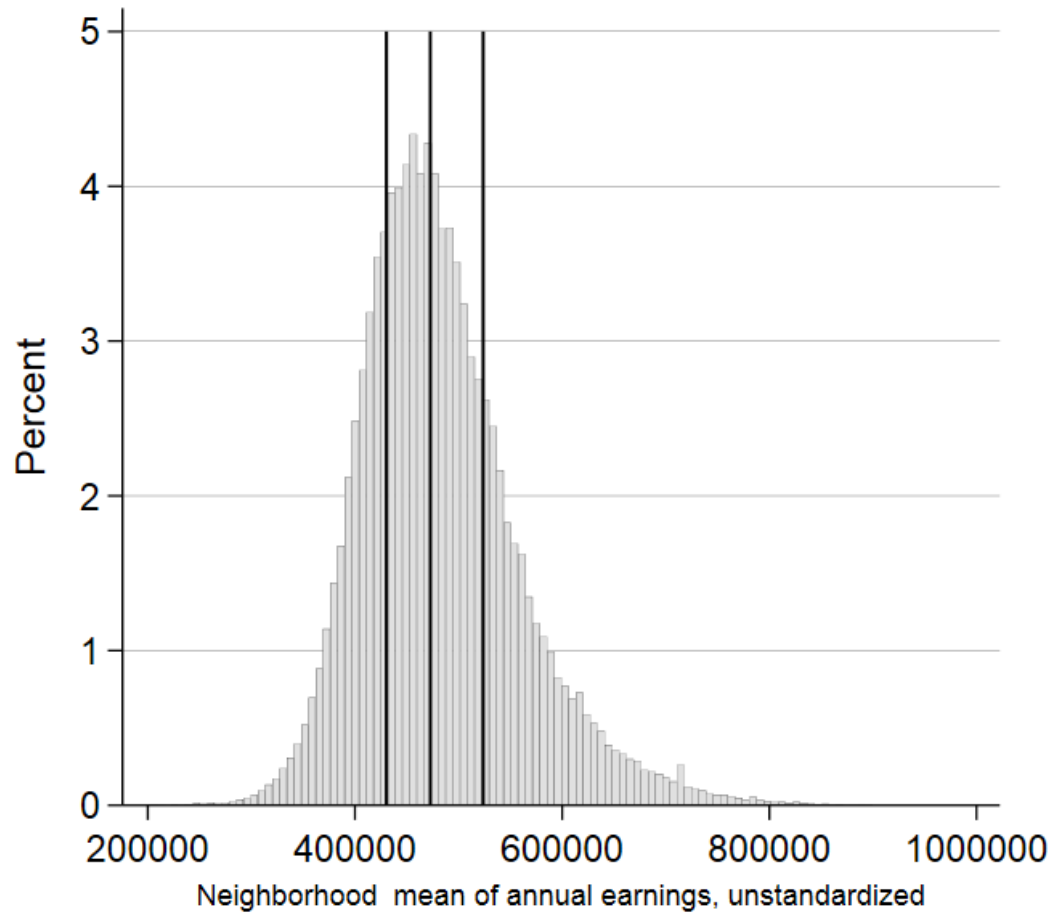

Figure A1. Economic neighborhood quartiles in childhood and adulthood measured in unstandardized Norwegian kroner (NOK) for our sample. Note: The vertical lines mark the division between each neighborhood quartile. 
(a) Ethnic neighborhood quartiles in childhood

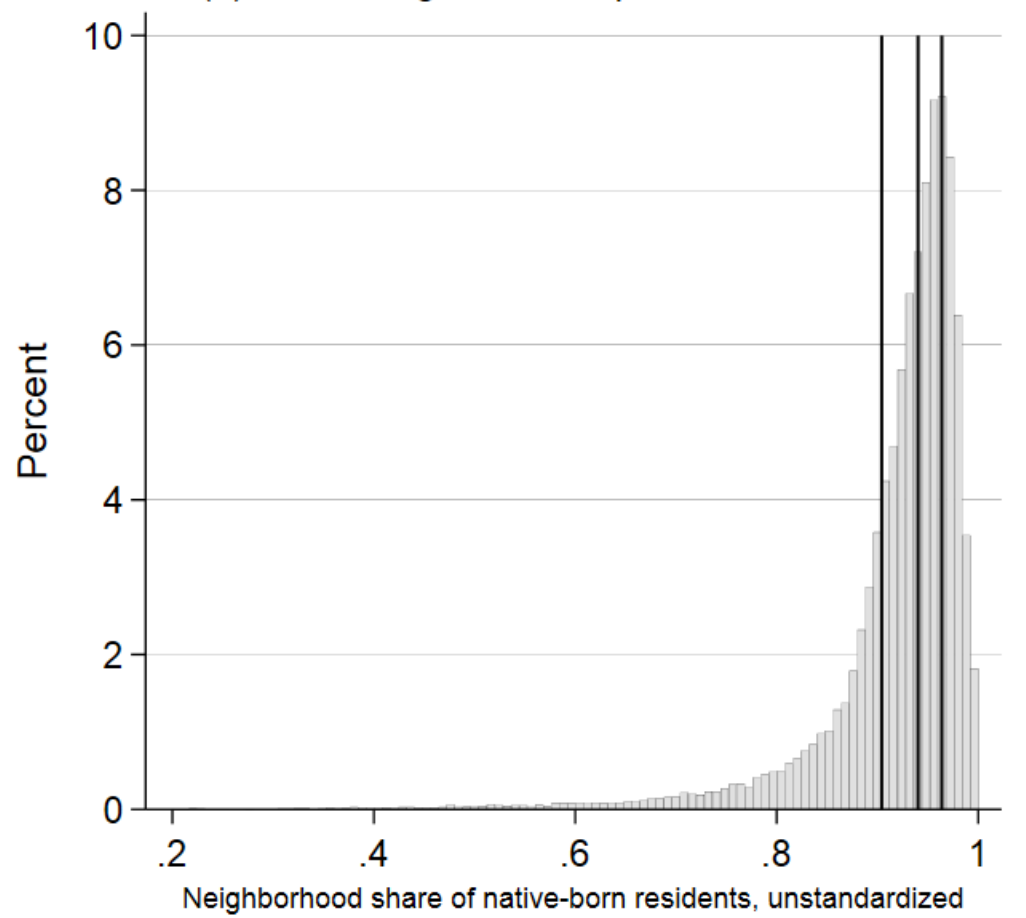

(b) Ethnic neighborhood quartiles in adulthood

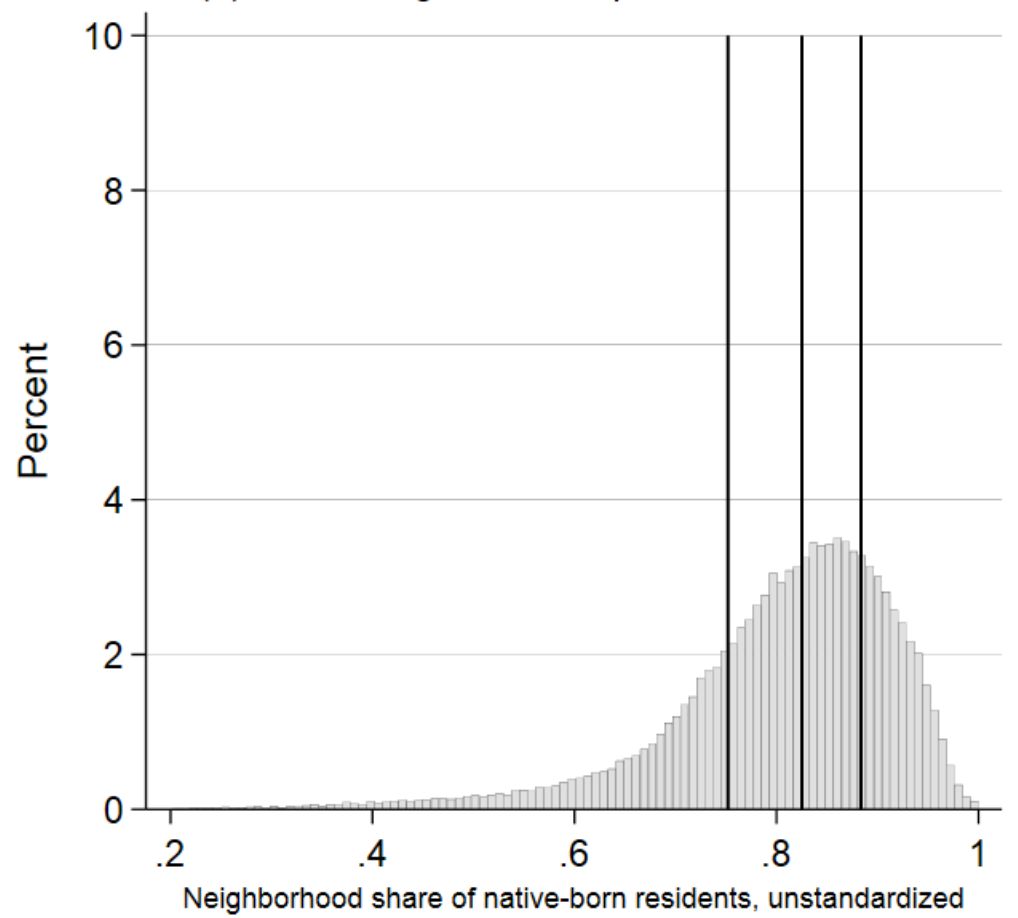

Figure A2. Ethnic neighborhood quartiles in childhood and adulthood measured in unstandardized shares of native-origin residents for our sample. Note: The vertical lines mark the division between each neighborhood quartile. 